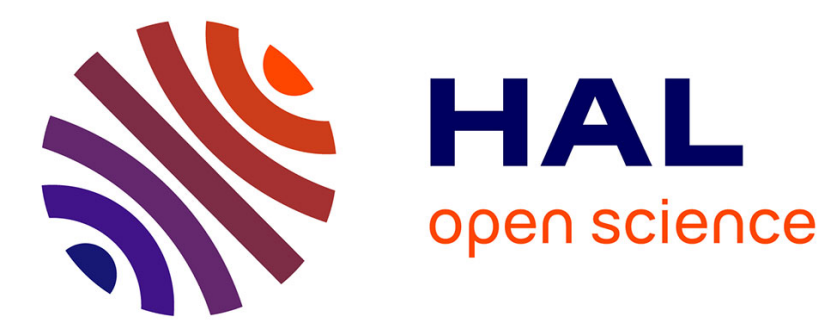

\title{
1 -Arginine-Catalyzed Synthesis of Nanometric Organosilica Particles through a Waterborne Sol-Gel Process and Their Porous Structure Analysis
}

\author{
X. Qiao, Pierre-Yves Dugas, Laurent Veyre, E. Bourgeat-Lami
}

\section{- To cite this version:}

X. Qiao, Pierre-Yves Dugas, Laurent Veyre, E. Bourgeat-Lami. 1 -Arginine-Catalyzed Synthesis of Nanometric Organosilica Particles through a Waterborne Sol-Gel Process and Their Porous Structure Analysis. Langmuir, 2018, 34 (23), pp.6784 - 6796. 10.1021/acs.langmuir.8b00042 . hal-01858561

\author{
HAL Id: hal-01858561 \\ https://hal.science/hal-01858561
}

Submitted on 7 Oct 2021

HAL is a multi-disciplinary open access archive for the deposit and dissemination of scientific research documents, whether they are published or not. The documents may come from teaching and research institutions in France or abroad, or from public or private research centers.
L'archive ouverte pluridisciplinaire HAL, est destinée au dépôt et à la diffusion de documents scientifiques de niveau recherche, publiés ou non, émanant des établissements d'enseignement et de recherche français ou étrangers, des laboratoires publics ou privés. 


\title{
L-arginine-catalyzed synthesis of nanometric organosilica particles through a waterborne sol-gel process and their porous structure analysis
}

\author{
X. G. Qiao, ${ }^{1,2 *}$ P-Y. Dugas, ${ }^{1}$ L. Veyre ${ }^{1}$ and E. Bourgeat-Lami ${ }^{1}{ }^{1}$
}

${ }^{1}$ Univ. Lyon, Université Claude Bernard Lyon 1, CPE Lyon, CNRS, UMR 5265, Chemistry, Catalysis, Polymers and Processes (C2P2), 43 Bvd. du 11 Novembre 1918, F-69616 Villeurbanne, France. ${ }^{2}$ College of Chemistry and Chemical Engineering, and Henan Key laboratory of Function-Oriented Porous Materials, Luoyang Normal University, Luoyang 471934, China.

Xiaoguang@lynu.edu.cn

bourgeat@1cpp.cpe.fr

\begin{abstract}
We report an efficient and easy to implement waterborne sol-gel process for the synthesis of nanometric organosilica particles. In this process, tetraethyl orthosilicate (TEOS) and 3-(methacryloxy)propyl trimethoxy silane ( $\gamma$-MPS), employed as silica sources, are heterogeneously delivered in an aqueous solution of L-arginine, a basic amino acid used as catalyst, from a top organic layer. Co-condensation of TEOS with $\gamma$-MPS led to organosilica particles with diameters comprised between 30 and $230 \mathrm{~nm}$ when increasing the $\gamma$-MPS content from 0 to $10.1 \mathrm{~mol} \%$ in the silica source. Nitrogen sorption analyses confirmed the microporous nature of the obtained particles after calcination. The Brunauer-Emmett-Teller (BET) surface areas increased from 27 (before calcination) to $684 \mathrm{~m}^{2} \mathrm{~g}^{-1}$ (after calcination) for the organosilica particles containing $10.1 \mathrm{~mol} \%$ of $\gamma$-MPS. Fourier transform infrared (FTIR) spectroscopy and ${ }^{29} \mathrm{Si}$ nuclear magnetic resonance (NMR) were employed to analyze the chemical structure of the organosilica spheres and provide insight into the mechanism of particle formation. In a second part, hybrid organosilica particles with a core-shell morphology were synthesized through the combination of Pickering emulsion and the sol-gel process. $\gamma$-MPS emulsion droplets stabilized by tiny silica particles (formed in a separate step)
\end{abstract}


were firstly generated, and used as seeds to grow a silica shell on their surface through TEOS addition from the top organic layer. TEM and pore size analyses of the resulting particles after calcination revealed a unique dual-porosity structure with a mesoporous inner core and a micro/mesoporous silica shell with ink-bottle type pores.

Keywords: Biphasic, sol-gel, waterborne, organosilica, L-arginine, hydrolysis, co-condensation, Pickering, mesoporous, core-shell, microporous, ink-bottle pores

\section{TOC GRAPHIC}

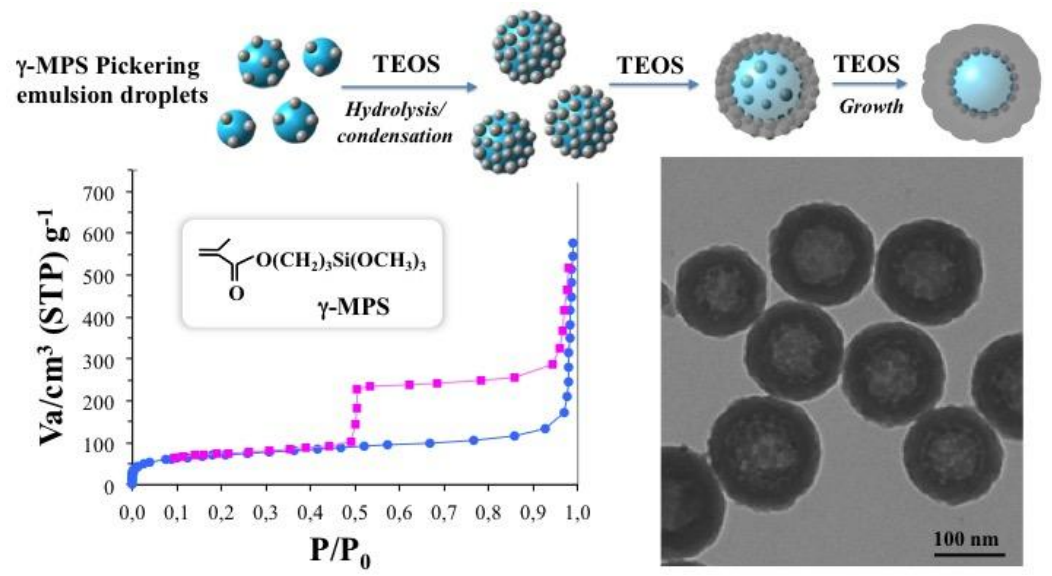




\section{INTRODUCTION}

Silica nanoparticles have been the focus of the majority of studies on oxide-based nanostructured materials. ${ }^{1}$ One main reason for this is its easy processability, high chemical inertness and exceptional colloidal stability. Moreover, silica can be processed as thin films or powders of controllable porosity. ${ }^{2}$ Since the discovery of mesoporous materials by Yanagisawa et al. ${ }^{3}$ and Kresge et al. ${ }^{4}$ in the early 1990's, significant progress has been made in the synthesis of ordered mesoporous materials with various compositions, structures, and morphologies. ${ }^{5,6}$ Mesoporous silica materials can provide scientists with several advantages. Mesoporous silica synthesized by using surfactant molecules as templates are highly stable, and have controlled pore sizes and narrow pore size distributions. They can be used in different fields, such as separation techniques, adsorption, catalysis, sensors, or photonics for instance. ${ }^{7,8,9}$ Among them, mesoporous silica particles have attracted increasing attention because of their huge potential in catalysis or medicine. ${ }^{10,11,12}$ To date, many different strategies have been developed for the synthesis of mesoporous silica nanoparticles (MSNs) including self-assembly, ${ }^{13,14}$ emulsion templating ${ }^{15}$ and post-etching. ${ }^{16,17}$ Among them, synergetic self-assembly between surfactants and a silica precursor (such as tetraethyl orthosilicate: TEOS) proved to be an efficient method to form uniform spherical MSNs. ${ }^{18,19,20,21}$ For instance, Suzuki et al. ${ }^{22}$ demonstrated that well-ordered MSNs with diameters lower than typically $100 \mathrm{~nm}$ can be prepared by using cetyltrimethylammonium chloride (CTAC) together with a nonionic triblock copolymer (Pluronic F127). The reaction was conducted in acidic conditions to allow complete hydrolysis of the alkoxide followed by an increase of $\mathrm{pH}$ to promote the assembly of the negatively charged silicate precursors with the positively charged CTA micelles. Recently, Yokoi et al. ${ }^{23}$ and Wang et al. ${ }^{24}$ described the direct synthesis of 15-200 $\mathrm{nm}$ diameter MSNs in basic conditions using a two-phase process where TEOS was slowly delivered in an aqueous solution containing amino acids or primary 
amines and CTAC as structure directing agent.

Silica particles can also be easily functionalized by the incorporation of specific organic groups. ${ }^{13}$ Compared to purely inorganic silica particles typically prepared by the Stöber method using TEOS as precursor, ${ }^{25}$ organosilica nanoparticles have potential applications in optics, ${ }^{26,27,28,29,30}$ functional materials, ${ }^{31,32}$ and biosciences ${ }^{33,34,35,36}$ due to their high surface reactivity, smaller negative surface charge and enhanced biological compatibility. Organosilica particles can be readily obtained by post-synthetic grafting of organoalkoxysilanes onto preformed silica particles. The terminal group of the alkoxysilane molecules can be reactive such as thiol, ${ }^{37}$ amino, ${ }^{38,39}$ epoxy, ${ }^{40}$ vinyl or methacrylate, or non-reactive (e.g., alkyl). ${ }^{41}$ One-pot synthetic approaches involving the homo-condensation or the co-condensation reaction between hydrolyzed organotrialkoxysilanes and silica precursors have also been reported. ${ }^{31,36,42,43}$ Such reactions are usually performed in hydro-alcoholic media (or in any other organic solvent that is miscible with water) which conditions ensure that an homogeneous solution of precursors is formed initially. There is an abundant literature on this topic and the interested reader is referred to recent reviews. ${ }^{1,44}$ In contrast, examples of synthesis of organosilica particles in aqueous solution (without the addition of co-solvent) remain scarce. For instance, Johnson, ${ }^{45}$ Miller ${ }^{35}$ or more recently Lee et al. $^{46}$ reported the preparation of monodisperse organosilica particles using 3-mercaptopropyl- or vinyl- trialkoxysilane precursors directly in water. An emulsion was formed initially by adding the organosilane to acidified water. The emulsion gradually broke down to give a clear solution as the silane progressively hydrolyzed, and an intermediate emulsion phase mainly composed of oligomeric species appeared. A base catalyst was finally introduced to promote the condensation reaction and form solid particles by cross-linking the short polymer chains. The particle size was controlled by the concentration of the organosilane and the reaction temperature. The method was further improved by Deng et al. ${ }^{47}$ 
who formed hybrid organosilica spheres with diameters comprised between 360 and $770 \mathrm{~nm}$ through strict control of the precursor and ammonia catalyst concentrations. Following a similar approach, van der Wel et al. $^{48}$ recently reported the synthesis of 3-(methacryloxy)propyl trimethoxy silane ( $\gamma$-MPS)-based microspheres in the absence of surfactant. Contrary to the previous examples, the silane precursor was directly injected in a solution of ammonium hydroxide used as catalyst leading to spontaneous emulsification of $\gamma$-MPS oligomeric droplets, which were solidified by polymerization. Hollow silica spheres were also prepared by Segers et al. ${ }^{49}$ using a related method and phenyl trimethoxysilane as precursor. An inconvenience of the self-emulsification process, however, is that it leads to relatively large particles with diameters in the range of 0.5 to several micrometers. The synthesis of monodisperse organosilica spheres in the nanometer range is indeed challenging. In order to decrease the hybrid particle size, Ottenbrite et al. ${ }^{50}$ and Meng et al. ${ }^{51}$ reported the use of surfactant molecules. However, surfactants can adversely affect the final material properties and are undesirable in many applications.

In this work, we report a simple surfactant-free method for the preparation of nanometric organosilica particles suspended in water using a biphasic sol-gel process. ${ }^{52,53}$ Our strategy relies on the co-condensation of TEOS and $\gamma$-MPS precursors, which are slowly delivered to an aqueous solution of L-arginine, used as catalyst. One of the key benefits of this process is that it does not require the use of surfactant or inert solvent. It was found that the hybrid particle size could be controlled by the molar ratio of the starting materials, which also revealed to be an important parameter influencing the colloidal stability of the resulting particles. Indeed, a too high $\gamma$-MPS content resulted in unstable suspensions. Building on this observation, we next developed a three steps process for the synthesis of organosilica particles with a core-shell morphology. A Pickering emulsion was first prepared using $\gamma$-MPS as the oil phase and nanometer silica particles - synthesized in situ - as solid stabilizer. The 
Pickering-stabilized $\gamma$-MPS droplets were then used as seeds for the subsequent growth of a silica shell on their surface resulting in the formation of core-shell particles with a $\gamma$-MPS core and an organosilica shell. The physicochemical and structural properties of the organosilica and core-shell organosilica particles were carefully analyzed before and after calcination using complementary characterization techniques. To the best of our knowledge this is the first report on the synthesis of organosilica particles with nanometer dimensions directly in aqueous solution, and also one of the rare examples of the formation of porous structures using the L-arginine-catalyzed two-phase reaction process.

\section{EXPERIMENTAL SECTION}

Materials. L-arginine ( $\geqq 98.5 \%$, Aldrich), tetraethyl orthosilicate (TEOS, $\geqq 99.0 \%$, Aldrich) and 3-(methacryloxy)propyl trimethoxy silane ( $\gamma$-MPS, 98\%, Aldrich) were used without further purification. Deionized water (Purelab Classic UV, ElgaLabWater) was used for all experiments.

Synthesis of hybrid organosilica particles. The hybrid organosilica particles were synthesized using the L-arginine catalyzed two-phase process following a procedure similar to the one described in the work of Hartlen et al. ${ }^{52}$ Typically, $25 \mathrm{~mL}$ of a $6 \mathrm{mmol} \mathrm{\textrm {L } ^ { - 1 }}$ L-Arginine solution were first introduced in a thermostated cylindrical reactor equipped with a reflux condenser and a magnetic stirrer bar (Figure S1 in the Supporting Information). Once the solution reached $60^{\circ} \mathrm{C}$, a mixture of TEOS and $\gamma$-MPS was added carefully on top of the reactor to get a two-phase solution. The stirring rate was fixed at $250 \mathrm{rpm}$ to mix the aqueous solution well, while keeping the top layer relatively undisturbed. The reaction was kept at $60^{\circ} \mathrm{C}$ for $72 \mathrm{~h}$. 
Synthesis of core-shell organosilica particles. The core-shell organosilica particles were synthesized in one pot following three steps. In a first step, $25 \mathrm{~mL}$ of a $6 \mathrm{mmol} \mathrm{L}^{-1} \mathrm{~L}$-arginine solution was introduced in a cylindrical reactor. Once the temperature reached $60^{\circ} \mathrm{C}, 0.5 \mathrm{~mL}$ of TEOS was added carefully to get a two-phase solution. This step was carried out for at least $48 \mathrm{~h}$ to reach full TEOS consumption leading to silica nanoparticles around $15 \mathrm{~nm}$ in diameter (Figure S2, Supporting Information). In a second step, various amounts of $\gamma$-MPS were introduced in the reactor. At the same time, the stirring speed was increased to $750 \mathrm{rpm}$ and this high speed was maintained for 30 min to form a stable emulsion. Finally, the stirring speed was reduced to $250 \mathrm{rpm}$ and TEOS $(5 \mathrm{~mL})$ was carefully added to the solution to get a two-phase mixture again. The reaction then proceeded at $60^{\circ} \mathrm{C}$ for $96 \mathrm{~h}$. Samples were withdrawn during the reaction to characterize the evolution of particle morphology with time.

Formation of porous silica particles. The organosilica and core-shell organosilica particles were calcined under air at $800^{\circ} \mathrm{C}$ for $24 \mathrm{~h}$ to remove the organic part of the silane molecule and generate porous particles. The mass before and after calcination is indicated in the Supporting Information (Table S1).

Characterizations. Dynamic light scattering (DLS, Nano ZS from Malvern Instruments) was used to measure the particle size (average hydrodynamic diameter, $\mathrm{Z}_{\mathrm{av}}$ ). The broadness of the distribution was given by a dimensionless number called poly value determined from the autocorrelation function using the second-order method of cumulant analysis (the higher this value, the broader the size distribution). Before measurement, the samples were diluted in deionized water and the reported particle size represents an average of 3 measurements. The silica and organosilica particles were imaged by transmission electron microscopy (TEM) with a Philips CM120 transmission electron microscope operating at an accelerating voltage of $80 \mathrm{kV}$ (Centre Technologique des Microstructures, plate-forme de l'Université Claude 
Bernard, Lyon 1). Highly diluted samples were dropped on a formvar-carbon coated copper grid and dried under air. The Pickering $\gamma$-MPS emulsion droplets were characterized by cryo-transmission electron microscopy (cryo-TEM). As described in details elsewhere, ${ }^{54}$ thin liquid films of $5 \mathrm{wt} \%$ suspensions were formed onto commercial holey carbon membranes (Quantifoil R2.1, Germany) and vitrified by quench freezing into liquefied ethane. The grids were then mounted in a Gatan 626 specimen holder, precooled with liquid nitrogen, and subsequently observed at $-180^{\circ} \mathrm{C}$, using a Philips CM120 Cryo microscope operating at $120 \mathrm{kV}$. The number-average $\left(D_{\mathrm{n}}\right)$ and the weight-average $\left(D_{\mathrm{w}}\right)$ diameters of the silica and organosilica particles were determined directly on the TEM micrographs according to: $D_{\mathrm{n}}=$ $\sum \mathrm{n}_{\mathrm{i}} D_{\mathrm{i}} / \Sigma \mathrm{n}_{\mathrm{i}}$ and $D_{\mathrm{w}}=\Sigma \mathrm{n}_{\mathrm{i}} D_{\mathrm{i}}^{4} / \Sigma \mathrm{n}_{\mathrm{i}} D_{\mathrm{i}}{ }^{3}$, where $\mathrm{n}_{\mathrm{i}}$ is the number of particles with diameter $D_{\mathrm{i}}$. A minimum of 150 particles was counted for each batch. Scanning electronic microscopy (SEM) was performed using a FEI QUANTA 250 FEG scanning electron microscope, at an acceleration voltage of $10 \mathrm{kV}$. A drop of the particle suspension was placed on a formvar/carbon film, dried and covered by a thin layer of platinum (6 nm, MED020 coating system, BAL-TEC, Germany) before analysis. Fourier transform infrared (FTIR) spectra were recorded from $\mathrm{KBr}$ pellets at room temperature using a Nicolet Avatar FTIR spectrometer. Background and sample were acquired using 32 scans at a spectral resolution of $4 \mathrm{~cm}^{-1}$ from 4000 to $400 \mathrm{~cm}^{-1}$. Spectral data were obtained using the OMNIC Software from Thermo Scientific. ${ }^{29} \mathrm{Si}$ solid-state NMR was performed on a Bruker DSX-300 spectrometer operating at $59.63 \mathrm{MHz}$. The spinning rate was $10 \mathrm{kHz}$. The ${ }^{29} \mathrm{Si}$ chemical shifts were referenced to tetramethylsilane. Nitrogen adsorption-desorption isotherms were recorded in a Micromeritics ASAP 2000 device. Prior to analysis, all samples were purged under a vacuum at $120^{\circ} \mathrm{C}$ overnight to remove surface water. Specific surface areas were estimated by using the Brunauer-Emmett-Teller (BET) approach while the t-plot method of de Boer et al. ${ }^{55}$ was used to determine the size and the volume of the micropores. The pore 
size distribution of the core-shell particles was calculated by applying the Barret-Joyner-Halenda (BJH) formalism to the desorption branch of the isotherm assuming a cylindrical pore geometry. Thermogravimetry analyses (TGA) were performed on a TGA Q50 from TA Instrument using a temperature ramp from 20 to $800^{\circ} \mathrm{C}$ at a heating rate of $10^{\circ} \mathrm{C} \mathrm{min}^{-1}$.

\section{RESULT AND DISCUSSION}

\section{Synthesis and characterization of hybrid organosilica particles}

The hybrid organosilica nanoparticles were synthesized using the two-phase L-arginine catalyzed aqueous method first reported by Yokoi $^{56}$ and Hartlen. ${ }^{52}$ In this liquid-liquid biphasic process, L-arginine, a basic amino acid, is used as catalyst in aqueous media, while the TEOS and $\gamma$-MPS mixture is delivered heterogeneously from the top organic layer to the aqueous phase. According to the literature, the very slow increase of the solution supersaturation and the weakly basic conditions are key factors to ensure the formation of size controlled monodisperse nanoparticles by this two-phase technique. ${ }^{57}$ The concentration of the L-arginine solution was set at $6 \mathrm{mM}$ giving an initial $\mathrm{pH}$ of 10.3 . To get a stable biphasic system and allow slow diffusion of the silica precursors in the reaction medium, the density of the top organic layer must be lower than that of pure water $\left(1.0 \mathrm{~g} \mathrm{~cm}^{-3}\right)$. Thus, the ratio of TEOS and $\gamma$-MPS in the mixture is very important considering the respective densities of TEOS $\left(0.933 \mathrm{~g} \mathrm{~cm}^{-3}\right)$ and $\gamma$-MPS $\left(1.055 \mathrm{~g} \mathrm{~cm}^{-3}\right)$. Here, the mixture was supposed to be an ideal solution whose density $\left(\rho_{x}\right)$ was determined according to:

$$
\frac{1}{\rho_{x}}=\sum\left(\frac{x_{i}}{\rho_{i}}\right)_{n}
$$

where $\boldsymbol{x}_{\mathbf{i}}$ is the mass fraction and $\rho_{i}$ the density of component $\mathrm{i}$ in the solution. As shown in Table 1 , the density of the $\gamma$-MPS/TEOS mixture was kept at values lower than $1.0 \mathrm{~g} \mathrm{~cm}^{-3}$. 
However, the monomer mixture quickly settled down into the water phase to form an unstable milky solution when the $\gamma$-MPS content in the organic phase was increased to 14.8 mol\% even though the density of the mixture was still lower than $1.0 \mathrm{~g} \mathrm{~cm}^{-3}$. In fact, according to van der Wel et al. ${ }^{48}$ the density of $\gamma$-MPS is closer to $1.235 \mathrm{~g} \mathrm{~cm}^{-3}$, whose value is significantly higher than the one provided by the supplier. Such a difference can account for our experimental observations as the density of the organic mixture would be then close to that of water.

Table 1. Experimental conditions and main characteristics of the organosilica particles synthesized in one step using a liquid-liquid biphasic sol-gel process. ${ }^{\text {a }}$

\begin{tabular}{|c|c|c|c|c|c|c|}
\hline No & $\begin{array}{c}\gamma \text {-MPS } \\
(\mathrm{mol} \%)^{b}\end{array}$ & $\begin{array}{c}\rho_{x} \\
\left(\mathrm{~g} \mathrm{~cm}^{-3}\right)^{\mathrm{c}}\end{array}$ & $\begin{array}{c}\mathbf{Z}_{\text {av }}(\mathrm{DLS}) \\
\quad(\mathbf{n m})\end{array}$ & $\begin{array}{l}\text { Poly value } \\
\text { (DLS) }\end{array}$ & $\begin{array}{c}D_{\mathbf{n}}(\mathrm{TEM}) \\
(\mathbf{n m})\end{array}$ & $\begin{array}{c}D_{\mathrm{w}} / D_{\mathrm{n}} \\
(\mathrm{TEM})\end{array}$ \\
\hline SJLA01 & 0 & 0.933 & 43.3 & 0.05 & 30 & 1.01 \\
\hline SLMT02 & 2.1 & 0.935 & 49.6 & 0.04 & 32 & 1.02 \\
\hline SLMT03 & 5.0 & 0.939 & 76.3 & 0.02 & 57 & 1.02 \\
\hline SLMT04 & 7.5 & 0.942 & 160.4 & 0.02 & 133 & 1.02 \\
\hline SLMT05 & 10.1 & 0.944 & 263.7 & 0.04 & 233 & 1.14 \\
\hline SLMT06 & 14.8 & 0.952 & 1020 & 0.18 & 830 & 1.26 \\
\hline
\end{tabular}

${ }^{a}$ All reactions were carried out at $60^{\circ} \mathrm{C}$ for $72 \mathrm{~h}$. Water: $25 \mathrm{~mL}$, TEOS: $4 \mathrm{~mL}$ and [L-arginine] $=6 \mathrm{mmol}$ $\mathrm{L}^{-1}$. ${ }^{\mathrm{b}}$ With respect to the total mole amount of the organic phase. ${ }^{\mathrm{c}}$ Density of the $\gamma$-MPS/TEOS mixture determined using equation (1).

\subsection{Particle size measurements}

The hybrid particles were characterized by DLS. As shown in Figure 1 and Table 1, the diameter of the organosilica particles increased from around $43 \mathrm{~nm}$ to more than $1 \mu \mathrm{m}$ with increasing the $\gamma$-MPS content from 0 to $14.8 \mathrm{~mol} \%$. The increase in particle size for $\gamma$-MPS contents lower than typically 10.1 mol\% (samples 2 - 5, Table 1) can tentatively be attributed to hydrophobic interactions due to $\gamma$-MPS incorporation into the silica particles. The hydrophobic moieties would favor particle aggregation to reduce the surface energy as the 
$\gamma$-MPS content increases. The corresponding low poly values nevertheless indicate that the final particles have a high colloidal stability and a narrow size distribution suggesting limited aggregation. However, when the MPS content was increased further to 14.8 mol\% (SLMT06, Table 1), the system was disturbed as the organic top-layer progressively mixed with the aqueous phase, resulting in a significant increase in particle size and poly value (Table 1 and Figure 1). This undesirable phenomenon spurred us to explore an alternative approach to generate organosilica spheres, which will be described in the second part of the manuscript.

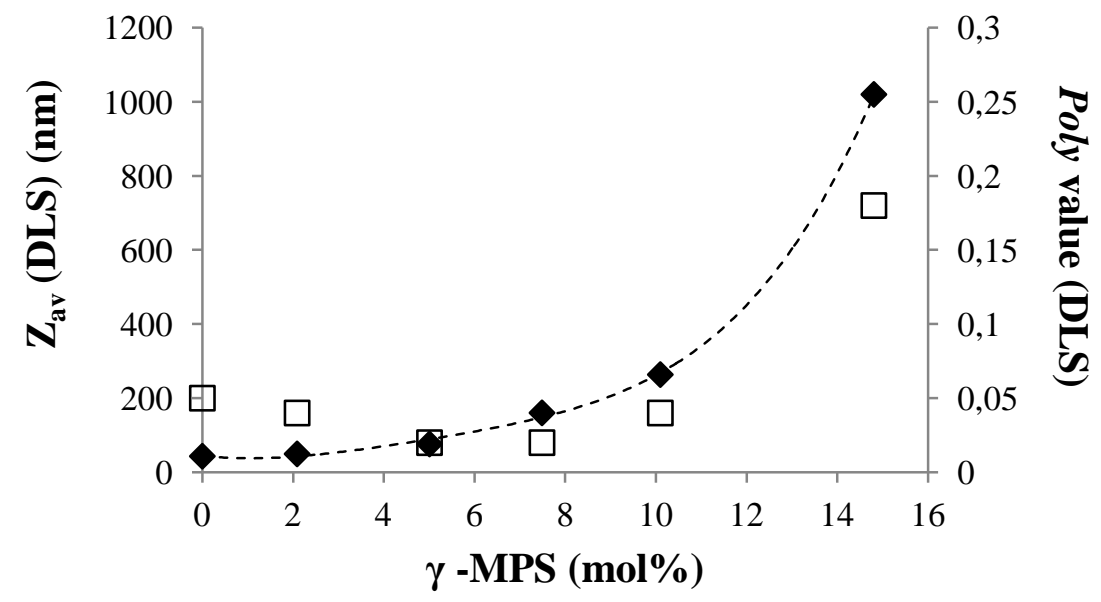

Figure 1. Evolution of the final diameter $\left(\mathrm{Z}_{\mathrm{av}},\right)^{-}$and poly value $(\square)$ of the organosilica particles for increasing $\gamma$-MPS contents in the organic phase.

\subsection{Chemical structure of the organosilica particles}

The FTIR spectra of pure silica and organosilica particles are shown in Figure 2. The bands in the $2850-3000 \mathrm{~cm}^{-1}$ region and at $1453 \mathrm{~cm}^{-1}$ are from the stretching of $\mathrm{CH}_{3}, \mathrm{CH}_{2}$ and $\mathrm{CH}$ groups ( $v$ and $\delta$ ) of $\gamma$-MPS while the peaks at $1050-1250 \mathrm{~cm}^{-1}$ are characteristic of C-O-C and $\mathrm{Si}-\mathrm{O}-\mathrm{Si}$ stretchings, providing clear evidence of $\gamma$-MPS incorporation in the organosilica spheres. In addition to an adsorption peak at $1635 \mathrm{~cm}^{-1}$ characteristic of the $\mathrm{C}=\mathrm{C}$ double bond stretching vibrations of $\gamma$-MPS overlapping with the $\delta \mathrm{OH}$ deformation band of physisorbed 
water at $1640 \mathrm{~cm}^{-1}$, the FTIR spectra of the organosilica particles show a strong band at 1701 $\mathrm{cm}^{-1}$ attributed to hydrogen-bonded carbonyl groups $(\mathrm{C}=\mathrm{O})$ of the silane moiety. ${ }^{58}$ Interestingly, this band increased in intensity as the $\gamma$-MPS content increased. Simultaneously, a new band appeared at $1719 \mathrm{~cm}^{-1}$ attributed to "free" non-bonded carbonyl groups. ${ }^{59}$ Based on these observations, it can be postulated that the organosilane molecules likely undergo condensation reactions with primary silica precursors formed in the very early stage of the process. ${ }^{60}$ At very low surface coverage, the chemisorbed silane molecules lie flat on the surface and the carbonyl groups of the methacrylate moiety form hydrogen bonds with the silanol groups of silica resulting in a shift of the $\mathrm{C}=\mathrm{O}$ band towards a lower wavenumber. ${ }^{61}$ As the $\gamma$-MPS concentration increases, a new carbonyl peak at $1719 \mathrm{~cm}^{-1}$ appeared, reflecting a new environment for the organosilane where free carbonyls predominate.

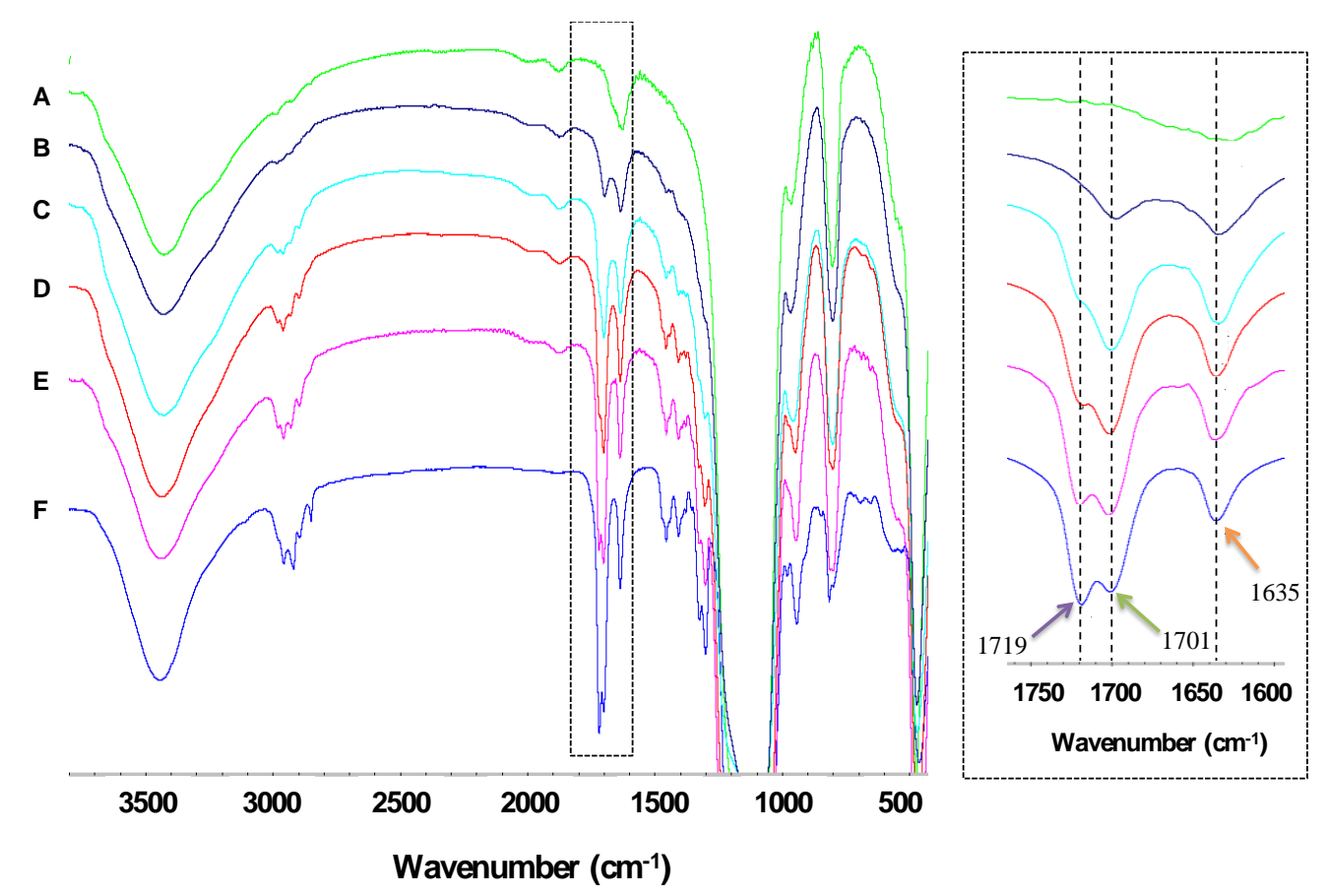

Figure 2. FTIR spectra of the organosilica particles for increasing $\gamma$-MPS contents. A: SLMT01 (0), B: SLMT02 (2.1 mol\%), C: SLMT03 (5.0 mol\%), D: SLMT04 (7.5 mol\%), E: SLMT05 (10.1 mol\%) and F: SLMT06 (14.9 mol\%) (see Table 1 for detailed experimental conditions). 
To gain further insight into the chemical structure of the organosilica particles, the samples were characterized by ${ }^{29} \mathrm{Si}$ solid-state NMR (Figure S3, Supporting Information). The different species are denoted according to the conventional $\mathrm{Q}^{\mathrm{n}}$ and $\mathrm{T}^{\mathrm{n}}$ notation where $\mathrm{Q}$ and $\mathrm{T}$ designate tetra- and tri-functional units, respectively, and $n$ is the number of bridging $\mathrm{O}$ atoms surrounding the silicon atom. ${ }^{62}$ The NMR spectrum of pure silica is characterized by two resonances at -110 and -101.4 ppm, which correspond respectively to $\mathrm{Q}^{4}$ and $\mathrm{Q}^{3}$ silicon atoms. The appearance in the ${ }^{29} \mathrm{Si}$ NMR spectra of signals assigned to mono- $\left(\mathrm{T}^{1}\right)$, di- $\left(\mathrm{T}^{2}\right)$ and tri$\left(\mathrm{T}^{3}\right)$ substituted siloxane units at $-48.5,-57$ and $-65.8 \mathrm{ppm}$, respectively, provides unambiguous evidence for TEOS and $\gamma$-MPS condensation reactions. It is worthwhile to note that, as expected, the relative intensities of the $T^{1}, T^{2}$ and $T^{3}$ signals increased with increasing $\gamma$-MPS content.

The thermal degradation behavior of the hybrid particles was further assessed by TGA under air atmosphere (Figure S4, Supporting Information). Thermal decomposition of the hybrid copolymers occurred in two steps. The first step between 250 and $450^{\circ} \mathrm{C}$ corresponds to the decomposition of the organic moiety of the silane molecule while the weight loss above $450^{\circ} \mathrm{C}$ is due to dehydroxylation. ${ }^{63}$ Interestingly, the thermal stability decreased with increasing the $\gamma$-MPS content as attested by a shift of the decomposition temperature at $5 \%$ weight loss to lower temperatures, while concurrently the weight loss residue at $800^{\circ} \mathrm{C}$ decreased since the fraction of volatile compounds increased with increasing silane content. These results thus indicate that incorporation of the organosilane into a silica-like network enhanced its thermal stability, which can be tentatively ascribed to the formation of a physical inorganic barrier preventing the release of the evolved degradation products. The higher the fraction of inorganic material, the better was the thermal stability. 


\subsection{Morphology and structure analyses}

TEM analysis of the organosilica particles confirmed that the particle size increased with increasing the $\gamma$-MPS content in the organic phase (Figure 3). The TEM diameters are in relative good agreement with DLS measurements (Table 1) although they are all smaller. Indeed, DLS measures the hydrodynamic diameter (with the solvation shell that surrounds the particles), and hydrodynamic diameters are always greater than the size determined by TEM. A direct comparison of the TEM image of Figure 3A (without $\gamma$-MPS) with all other TEM images clearly shows that the organosilica particles have a rough surface conferring an irregular appearance to the smallest particles.
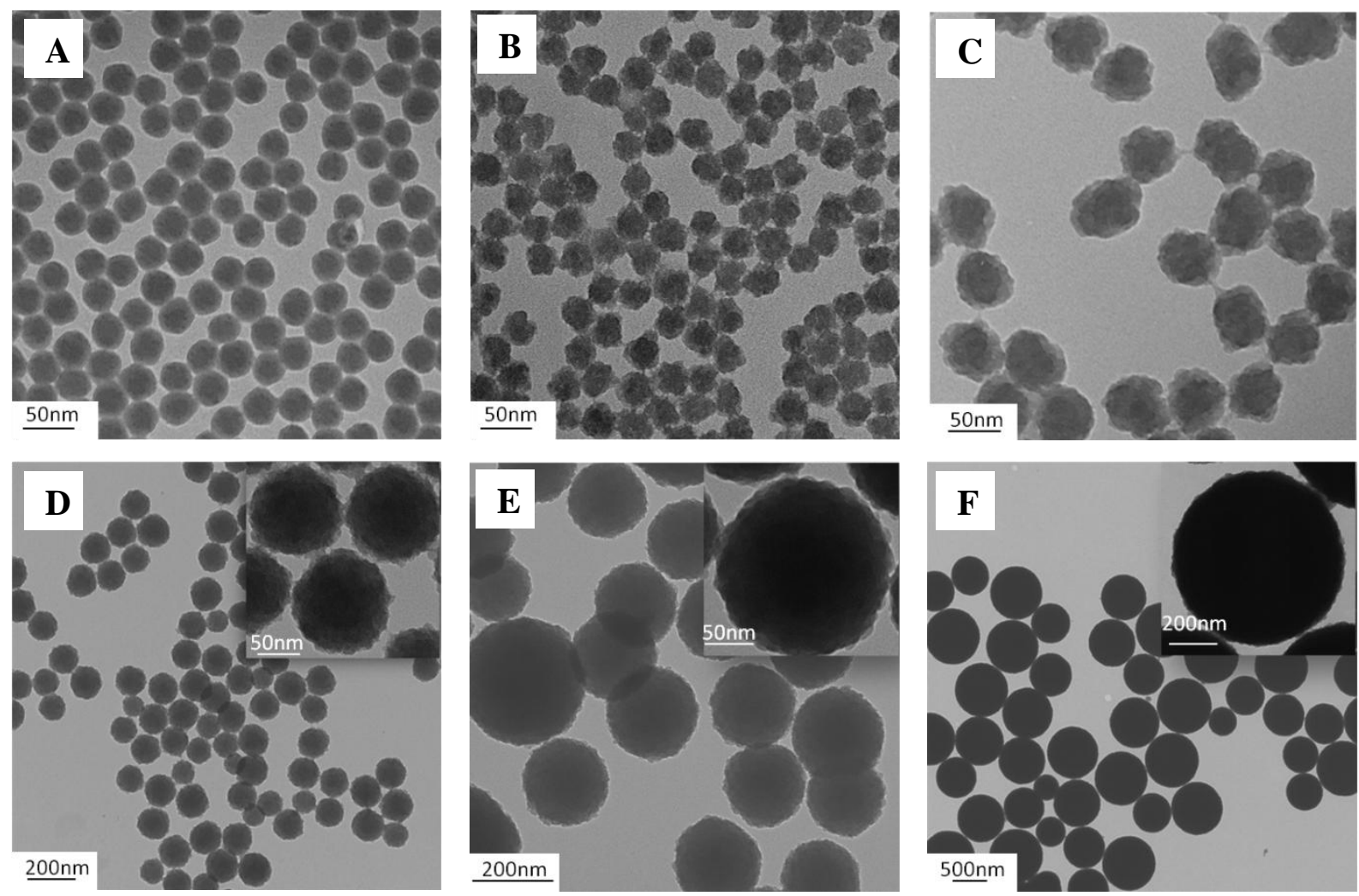

Figure 3. TEM images of the organosilica particles for increasing $\gamma$-MPS contents. A: SJLA01 (0), B: SLMT02 (2.09 mol\%), C: SLMT03 (5.0 mol\%), D: SLMT04 (7.5 mol\%), E: SLMT05 (10.1 mol\%) and F: SLMT06 (14.8 mol\%) (see Table 1 for detailed experimental conditions). 
SEM observations of the hybrid particles further confirmed the irregular shape and the surface roughness, which decreased as the particle size increased (Figure 4).
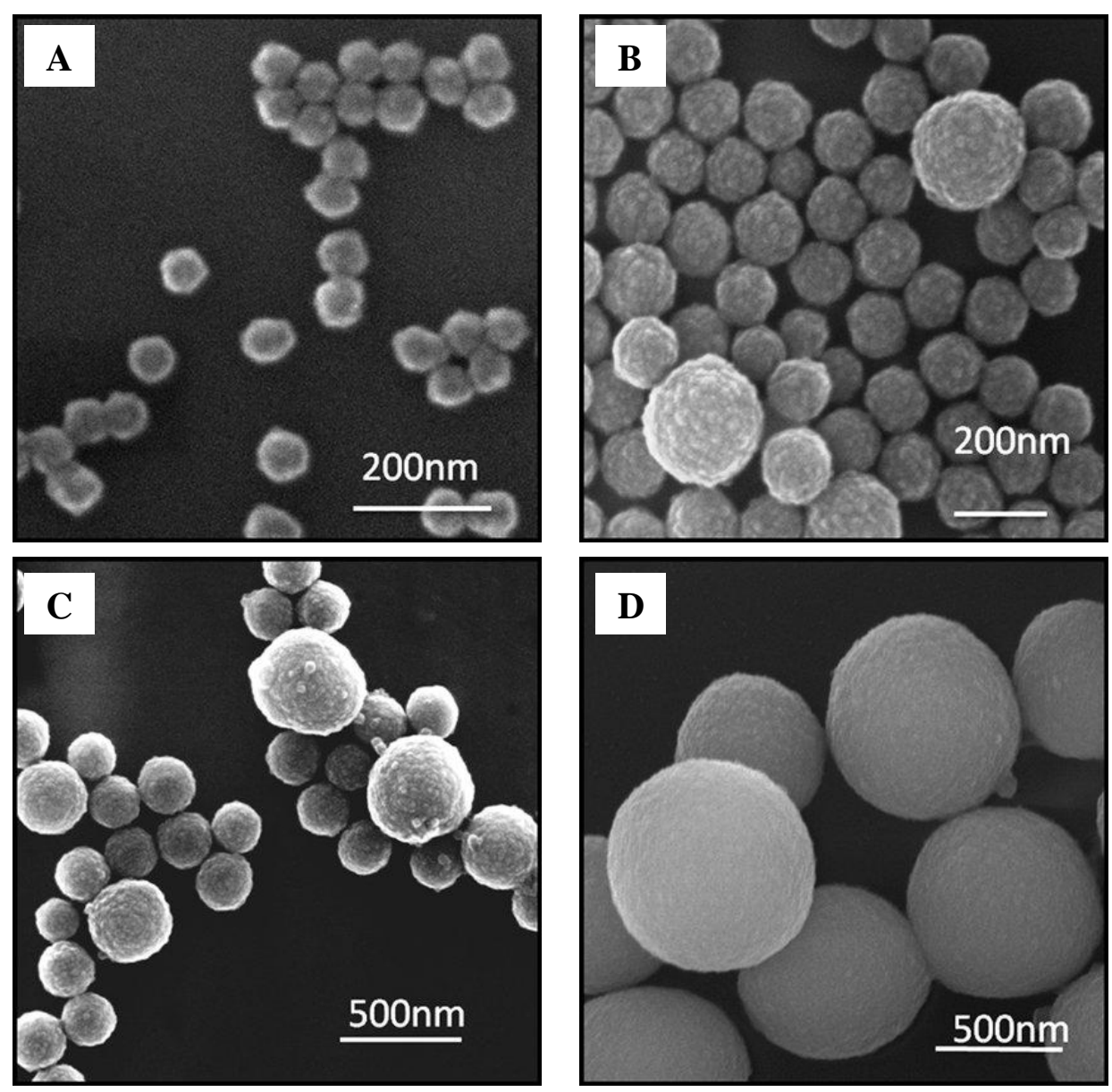

Figure 4. SEM images of organosilica particles for increasing $\gamma$-MPS contents. A: SLMT03 (5.0 mol\%), B: SLMT04 (7.5 mol\%), C: SLMT05 (10.1 mol\%) and D: SLMT06 (14.8 mol\%) (see Table 1 for detailed experimental conditions).

A similar rough surface was observed in the literature during the synthesis of mesoporous silica nanoparticles using a cationic surfactant as porogen, ${ }^{17,24,64}$ and is typical of assemblies produced in water. Indeed, according to Carcouët et al., ${ }^{60}$ silica particles prepared in aqueous media using amino acids as catalysts have a rougher surface than Stöber particles. In both cases, it is hypothesized that primary particles are formed initially, that first aggregate to form larger particles and then grow by further addition of monomer, short polymer or primary 
nuclei. However, in the Stöber process, the reversible exchange of alkoxy (Si-OR) and hydroxyl $(\mathrm{Si}-\mathrm{OH})$ groups creates a relaxation mechanism promoting smoothening, while in pure water the formation of Si-O-Si bonds is irreversible leading to silica assemblies with rough surfaces. As the particles size increases, further condensation of short oligomers or primary particles tends to increase the homogeneity and surface smoothness leading to more regular particles. ${ }^{60,65}$

Figure S5 shows the nitrogen adsorption-desorption isotherms of the hybrid particles before and after calcination for increasing amounts of $\gamma$-MPS (samples 3, 4 and 5 in Table 1). All isotherms are of type IV according to the IUPAC classification. As shown in Table 2, the BET specific surface area of the hybrid particles before calcination decreased with increasing the $\gamma$-MPS content, which can be attributed to the concomitant increase of particle size. After removal of the organic group by calcination, the specific surface area increased further due to the formation of micropores as attested by the larger nitrogen uptake in the low pressure range. The micropore volume determined by the t-plot method varied from 0.135 to 0.275 $\mathrm{cm}^{3} \mathrm{~g}^{-1}$, and increased with increasing the $\gamma$-MPS content (Table 2). These results thus demonstrate that $\gamma$-MPS is not only a silicate source, but also a mesostructural template.

Table 2. BET surface area before and after calcination, pore diameter and micropore volume determined by the t-plot method after calcination, for increasing $\gamma$-MPS contents.

\begin{tabular}{|c|c|c|c|c|c|}
\hline \multirow{2}{*}{$\mathbf{N}^{\circ}$} & \multirow{2}{*}{$\begin{array}{c}\gamma \text {-MPS } \\
(\mathrm{mol} \%)^{\mathrm{a}}\end{array}$} & \multicolumn{2}{|c|}{$S_{\text {BET }}\left(m^{2} g^{-1}\right)$} & \multirow{2}{*}{$\begin{array}{c}\begin{array}{c}\text { Pore diameter } \\
(\mathbf{n m})\end{array} \\
\begin{array}{c}\text { After } \\
\text { calcination }\end{array}\end{array}$} & \multirow{2}{*}{$\begin{array}{c}\begin{array}{c}\text { Micropore volume } \\
\left(\mathrm{cm}^{3} \mathrm{~g}^{-1}\right)\end{array} \\
\begin{array}{c}\text { After } \\
\text { calcination }\end{array}\end{array}$} \\
\hline & & $\begin{array}{c}\text { Before } \\
\text { calcination }\end{array}$ & $\begin{array}{c}\text { After } \\
\text { calcination }\end{array}$ & & \\
\hline SLMT03 & 5.0 & 114 & 475 & 4.4 & 0.135 \\
\hline SLMT04 & 7.5 & 82 & 644 & 4.3 & 0.238 \\
\hline SLMT05 & 10.1 & 27 & 684 & 3 & 0.275 \\
\hline
\end{tabular}

\footnotetext{
${ }^{a}$ With respect to the total mole amount of the organic phase (see Table 1 for more details).
} 
Figure 5 shows the TEM images of the three samples (SLMT03, 04 and 05, Table 1) after calcination. Compared with the original hybrid particles (Figure 3), the removal of the organic part had little effect on particle morphology except for the highest $\gamma$-MPS content, for which some hollow particles could be clearly observed in Figure 5C. Indeed as mentioned above, the density of the organic phase increased with increasing the $\gamma$-MPS content leading to the formation of $\gamma$-MPS-rich emulsion droplets by self-emulsification, which after reaction with TEOS and calcination formed hollow spheres.
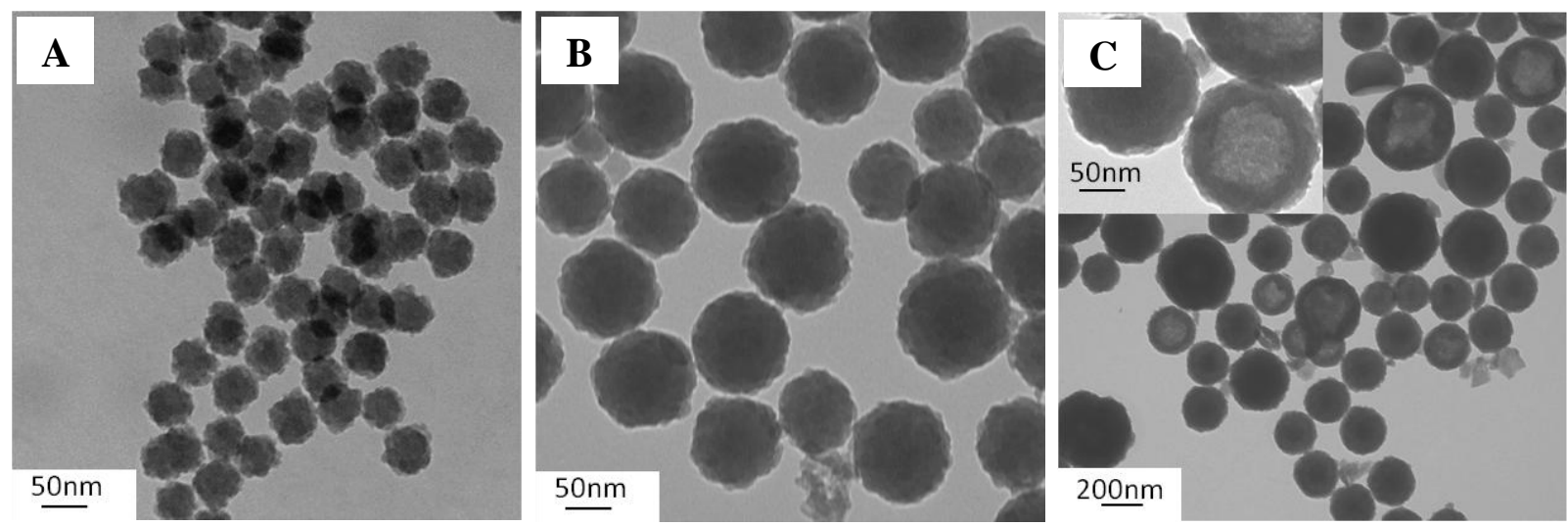

Figure 5. TEM images of the organosilica particles after calcination for increasing $\gamma$-MPS contents. A: SLMT03 (5.0 mol\%), B: SLMT04 (7.5 mol\%) and C: SLMT05 (10.1 mol\%) (see Table 1 for detailed experimental conditions).

On the basis of these results and the previous literature, we propose the following mechanism for the formation of the organosilica particles. In a first step, the TEOS $\gamma$-MPS mixture is hydrolyzed and slowly released in the aqueous solution containing L-arginine used as catalyst, leading to the formation of primary particles. According to the literature, ${ }^{53,66}$ the slow hydrolysis of the inorganic precursors (either TEOS or $\gamma$-MPS) is the rate-limiting step during the formation of the primary nanoparticles in such biphasic conditions. The hydrolysis rate in turn depends on various parameters including the geometry of the reactor, the stirring rate, 
the volume and composition of the organic phase, the L-arginine concentration and the temperature. ${ }^{57}$ Everything else being equal, it is reasonable to assume that in the present study, TEOS hydrolyses faster than $\gamma$-MPS as it is present in a fairly higher proportion in the organic mixture. Furthermore, according to the literature, the reaction rate between a hydrolyzed TEOS molecule and a hydrolyzed $\gamma$-MPS molecule is likely much smaller than that between two hydrolyzed TEOS molecules. This would thus lead to the formation of primary silica particles onto which $\gamma$-MPS molecules could subsequently bind as supported by FTIR analysis. As the silane content in the precursor solution increases, the probability of $\gamma$-MPS homo-condensation reactions also increases leading to the appearance of free carbonyl groups in the condensation products. Densification of the oligomeric structures formed in the earlier stages of the reaction would thus lead to primary organosilica particles with a silica core and a $\gamma$-MPS-rich shell. In order to minimize their surface contact with water and hence decrease the associated surface energy, these primary particles would soon aggregate into larger organosilica spheres stabilized by negative charges on their surface (arising from silanol groups deprotonation), and containing hydrophobic methacryloyloxy moieties buried in the particle core as schematically represented in Scheme 1. The resulting assemblies would finally grow by the continuous addition of primary particles formed in solution leading to rough surfaces.

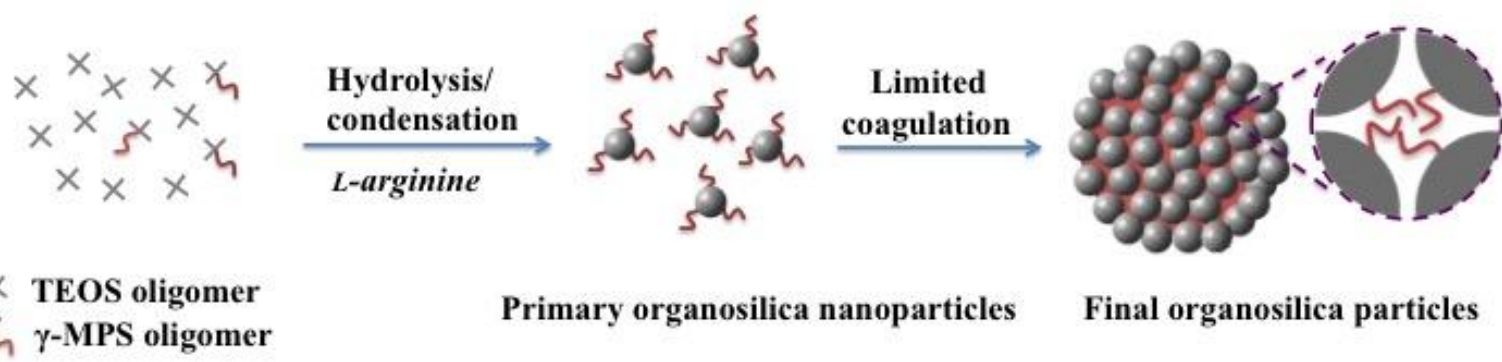

Scheme 1. Schematic illustration of the formation mechanism of the organosilica particles 
using a one-step liquid-liquid biphasic sol-gel process.

\section{Synthesis and characterization of core-shell organosilica particles using Pickering $\gamma$-MPS droplets as seeds}

As shown in the previous section, the addition of a too large amount of $\gamma$-MPS disturbed the top organic layer leading to the formation of a milky suspension, which after polymerization resulted in hybrid particles with a broad size distribution and a heterogeneous morphology. Based on this result, an extension of the biphasic process was thus investigated in order to control this undesirable phenomenon and form well-defined core-shell organosilica particles.

Our strategy builds on the recent observation of Sacanna et al. ${ }^{67,68}$ that $\gamma$-MPS can spontaneously form oil-in-water Pickering emulsions in the presence of inorganic particles. Hence, a Pickering emulsion composed of $\gamma$-MPS droplets stabilized by very small silica nanoparticles was first generated. As described in the experimental part, the silica nanoparticles were synthesized in a separate step using the same liquid-liquid biphasic process in which the $\gamma$-MPS/TEOS mixture was replaced by pure TEOS. The addition of 0.5 $\mathrm{mL}$ of TEOS enabled to get $15 \mathrm{~nm}$ diameter silica nanoparticles (Figure S2 in the Supporting Information) with $100 \%$ conversion $\left(\left[\mathrm{SiO}_{2}\right]=5.4 \mathrm{~g} \mathrm{~L}^{-1}\right) \cdot \gamma$-MPS was then added directly to the aqueous silica dispersion in the same reactor, and the mixture was stirred at $750 \mathrm{rpm}$ for 30 minutes. Carefully observed by eyes, the color of the suspension changed from white opaque to light blue in around $10 \mathrm{~min}$ indicating the formation of small Pickering-stabilized emulsion droplets. Cryo-TEM analysis confirmed the formation of small droplets around 45 $\mathrm{nm}$ in diameter, stabilized by a small number of silica particles (Figure 6A). The experiment was repeated two times leading to very similar results, attesting for the robustness of the 
Pickering emulsification process (Figure 6B).
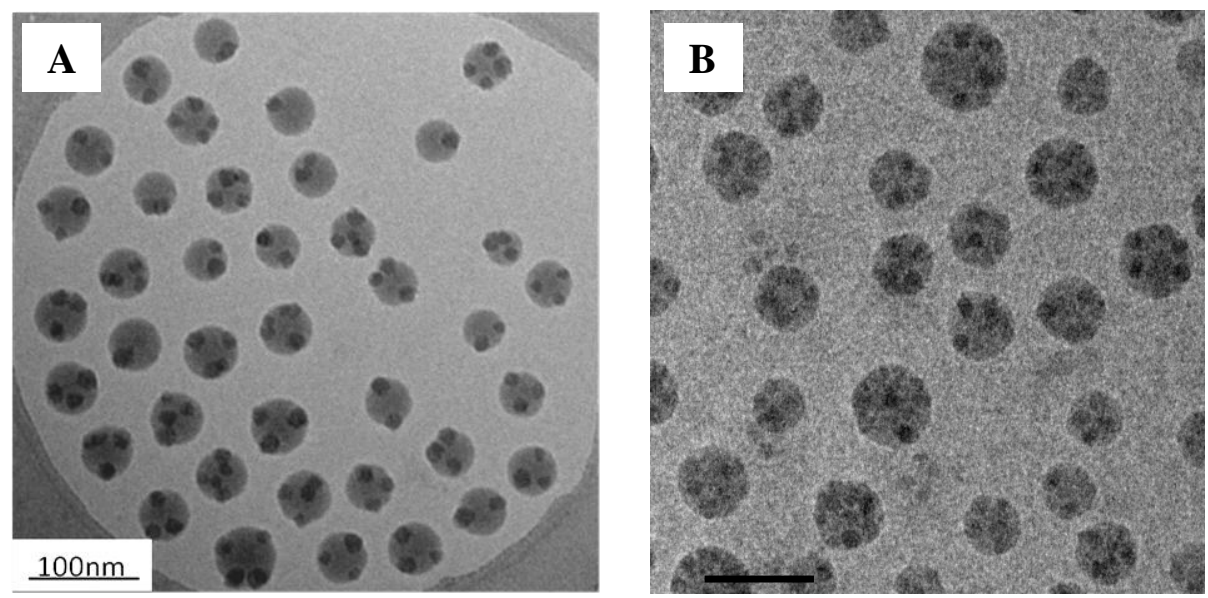

Figure 6. Cryo-TEM images of $\gamma$-MPS Pickering emulsion droplets stabilized by very small silica nanoparticles $(15 \mathrm{~nm}$ in diameter) synthesized in a separate step. The two images correspond to duplicate experiments showing the reproducibility of the Pickering emulsion formed after stirring at $750 \mathrm{rpm}$ for 30 minutes. Scale bar $=100 \mathrm{~nm}$.

After 30 minutes stirring, TEOS was introduced in the reactor and the speeding rate was reduced to $250 \mathrm{rpm}$ so as not to disturb the top organic layer during the subsequent growth step. Figure 7A shows the morphology of the $\gamma$-MPS droplets 1 hour after TEOS addition. The diameter of the $\gamma$-MPS droplets increased from 45 to around $60 \mathrm{~nm}$ while the morphology evolved from multipod (Figure 6) to raspberry-like (Figure 7). The increase in droplet size suggests that only a fraction of the bulk monomer was consumed initially to form the Pickering emulsion, the remaining part being progressively taken up by the nucleated droplets. In other words, the droplet size increased until full consumption of the monomer reservoir. Van de Wel et al. also reached a similar conclusion in their recent work on the formation of $\gamma$-MPS droplets by self-emulsification. ${ }^{48}$ Besides, cryo-TEM analysis provided clear evidence of the presence of residual monomer, which can be identified in Figure S7 (Supporting Information) as cloudy (diffuse) structures next to the $\gamma$-MPS Pickering emulsion 
droplets. The addition of TEOS to the Pickering emulsion induced the formation of a new crop of tiny silica particles that immediately adsorbed at the surface of the droplets, further contributing to their stabilization. Silica adsorption was in turn promoted by the concomitant grafting of organosilane molecules at their surface. The droplets became consequently fully covered with silica particles and exhibited a raspberry morphology up to 7 hours after TEOS addition (Figures 7A and 7B). Shell growth then occurred through further deposition of primary silica or organosilica particles leading to a more homogeneous shell over time. We can note that a granular shell was however still apparent after 48 hours and that the shell thickness continued increasing, and became visibly smoother only after full TEOS consumption.
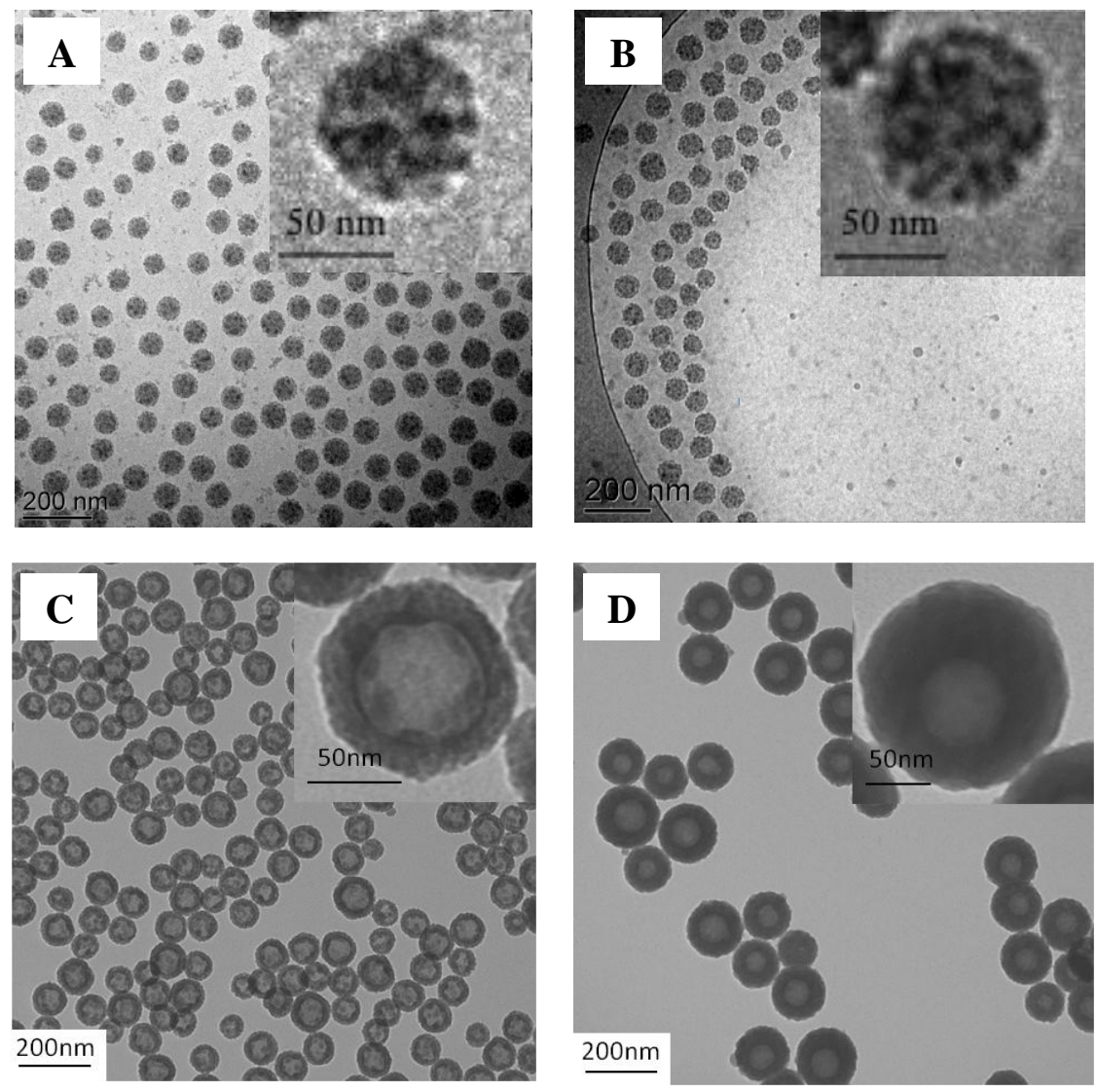

Figure 7. Cryo-TEM (A, B) and TEM (C and D) images of core-shell organosilica particles as a function of reaction time (SLMT09). A) 1h, B) 7h, C) $48 \mathrm{~h}$ and D) $96 \mathrm{~h}$. The morphology 
evolved from raspberry-like droplets to core-shell particles (from A to D). The inset shows a magnified portion of the image (see Table 3 for detailed experimental conditions).

\subsection{Effect of the $\gamma$-MPS concentration}

Table 3 and Figure 8 show the effect of the $\gamma$-MPS concentration on the diameter and morphology of the core-shell particles. DLS shows that when the concentration of $\gamma$-MPS was too low (i.e., $2.3 \mathrm{~mol} \%$, SLMT07), the poly value of the particles was very high. TEM revealed the formation of a few core-shell particles surrounded by many free silica particles (which appear as small grey spots), indicating that the amount of $\gamma$-MPS introduced was insufficient to absorb all the silica particles (Figure 8A). The population of free silica particles vanished when the concentration of $\gamma$-MPS was increased to 4.9 and then 9.9 mol\% (Figures $8 \mathrm{~B}$ and $8 \mathrm{C}$, respectively). As seen in Table 3, the diameter of the $\gamma$-MPS droplets depends on the MPS content and increased from 20 to $60 \mathrm{~nm}$ with increasing the MPS concentration from 2.3 to 9.9 mol\%. Consequently the shell thickness increased from $28 \mathrm{~nm}$ to $43 \mathrm{~nm}$ as there were initially less droplets for SLMT09 than for SLMT08. The shell thickness also depends on the reaction time and increased from $15 \mathrm{~nm}$ after $48 \mathrm{~h}$ to $43 \mathrm{~nm}$ after 96h, as determined from the TEM images (Figure 7).

Table 3. Effect of the $\gamma$-MPS concentration on the main characteristics of the $\gamma$-MPS droplets and the core-shell organosilica particles obtained by the L-arginine-catalyzed two-phase process using the Pickering emulsion droplets as seeds. ${ }^{a}$

\begin{tabular}{cccccccc}
\hline & & Core & \multicolumn{5}{c}{ Core-shell particles } \\
\hline No & $\begin{array}{c}\boldsymbol{\gamma} \text {-MPS } \\
(\mathbf{m o l} \%)\end{array}$ & $\begin{array}{c}\boldsymbol{D}_{\mathbf{n}} \\
(\mathbf{T E M}) \\
\mathbf{n m}\end{array}$ & $\begin{array}{c}\mathbf{Z}_{\mathbf{a v}} \\
(\mathbf{D L S}) \\
(\mathbf{n m})\end{array}$ & $\begin{array}{c}\text { Poly } \\
\text { value } \\
(\mathbf{D L S})\end{array}$ & $\begin{array}{c}\boldsymbol{D}_{\mathbf{n}} \\
(\mathbf{T E M}) \\
(\mathbf{n m})\end{array}$ & $\begin{array}{c}\boldsymbol{D}_{\mathbf{w}} / \boldsymbol{D}_{\mathbf{n}} \\
(\mathbf{T E M})\end{array}$ & $\begin{array}{c}\text { Shell } \\
\text { thickness } \\
(\mathbf{n m})\end{array}$ \\
\hline SLMT07 & 2.3 & 20 & 131 & 0.45 & $/$ & $/$ & $/$ \\
SLMT08 & 4.9 & 31 & 156 & 0.09 & 87 & 1.04 & 28 \\
SLMT09 & 9.9 & 60 & 194 & 0.05 & 146 & 1.03 & 43 \\
\hline
\end{tabular}


${ }^{a}$ All reactions were carried out at $60^{\circ} \mathrm{C}$ for $96 \mathrm{~h}$. Silica suspension: $25 \mathrm{~mL}\left(\left[\mathrm{SiO}_{2}\right]=5.4 \mathrm{~g} \mathrm{~L}^{-1}\right)$, TEOS: 5 $\mathrm{mL}$ and [L-arginine] $=6 \mathrm{mmol} \mathrm{L}^{-1}$. ${ }^{\mathrm{b}}$ With respect to the mole amount of TEOS added to form the shell.
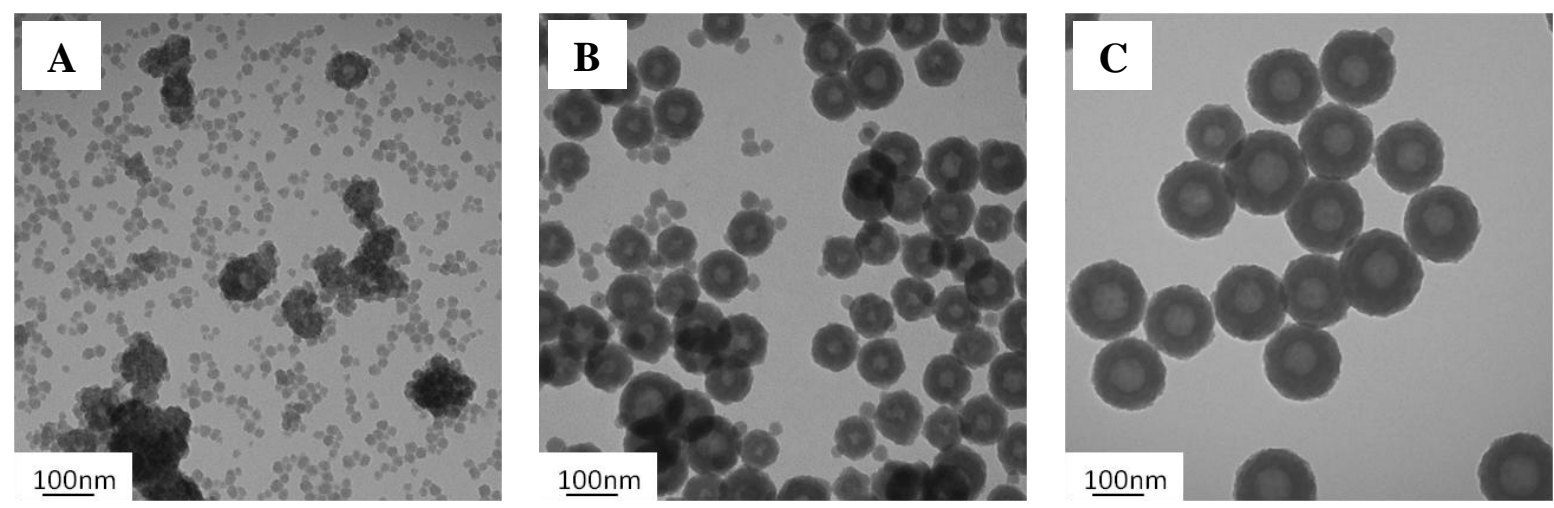

Figure 8. Effect of $\gamma$-MPS content on the morphology of the core-shell organosilica particles.

A: SLMT07 (2.3 mol\%), B: SLMT08 (4.9 mol\%) and C: SLMT09 (9.9 mol\%) (see Table 3 ).

\subsection{Structural characterizations}

Figure 9 shows the TEM images of SLMT08 and SLMT09 after calcination. At first sight, these images are very similar to the ones of Figure 8 before calcination. However, a closer look at Figure 9B reveals the presence of white spots in the particle core corresponding to the void spaces created upon removal of the organic porogen by calcination.
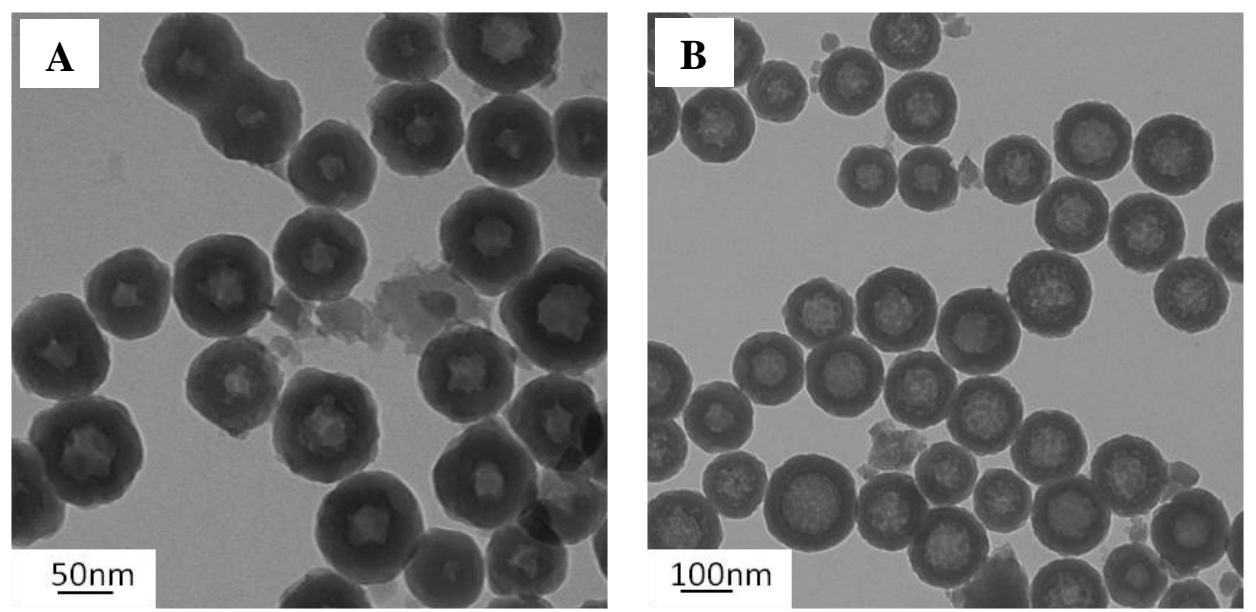

Figure 9. TEM images of the core-shell organosilica particles after calcination for two 
different $\gamma$-MPS contents. A: SLMT08 (4.9 mol\%) and B: SLMT09 (9.9 mol\%) (see Table 3 for detailed experimental conditions).

The $\mathrm{N}_{2}$ adsorption-desorption isotherm of the core-shell particles after calcination (SLMT09, Figure 10A) exhibits a type IV shape showing a desorption branch with a pronounced hysteresis loop of type $\mathrm{H} 4$ usually observed for complex materials that contain both micropores and mesopores. ${ }^{69}$ The amount of adsorbed $\mathrm{N}_{2}$ gradually raised at low relative pressure, reached a long pseudo-plateau and then increased significantly at higher relative pressure $\left(\mathrm{P} / \mathrm{P}_{0}=0.9-1.0\right)$.
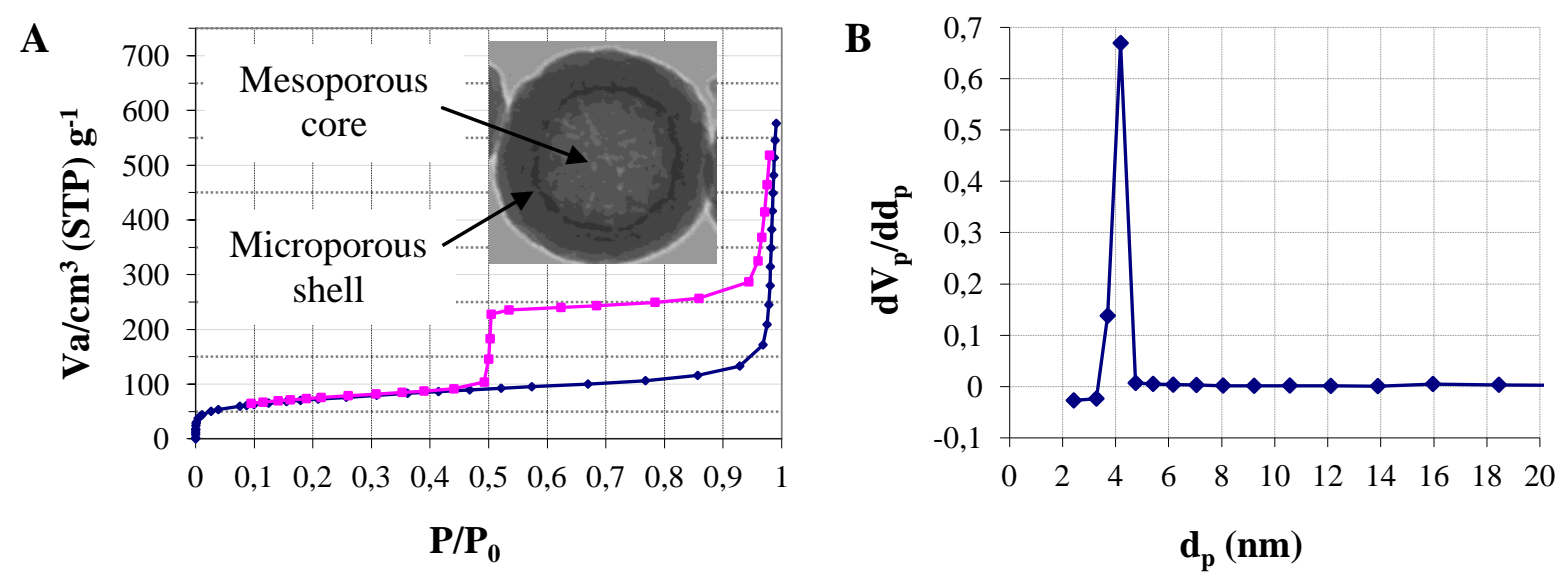

Figure 10. A) Nitrogen adsorption (ADS, $\downarrow$ ) and desorption (DES, $\square$ ) isotherms and B) BJH pore-neck size distribution of SLMT09 after calcination (see Table 3 for detailed experimental conditions).

Nitrogen uptake at very low pressures is due to monolayer adsorption of nitrogen molecules in the micropores. As will be discussed in more details below and by analogy with the organosilica spheres described above, the micropores most likely originate from the pyrolysis of the organic ligand entrapped in the organosilica shell. The sharp increase in nitrogen uptake for high relative pressures is due to the filling by capillary condensation of both the 
interparticle voids and the hollow cavities in the particle core. Also associated to the capillary condensation, the isotherm exhibits a strong hysteresis in the desorption branch over the pressure range of $\mathrm{P} / \mathrm{P}_{0}=0.5-1.0$ with two inflection points corresponding to $\mathrm{N}_{2}$ evaporation from the interparticle voids and the hollow cavity, respectively. The desorption branch exhibits a sharp drop at $\mathrm{P} / \mathrm{P}_{0}=0.5$ which corresponds to the delay of $\mathrm{N}_{2}$ evaporation from the hollow voids blocked by the surrounding micro/mesoporous shell during the desorption step. ${ }^{70}$ Such a behavior is typical of hollow mesoporous spheres and is often referred to as the ink-bottle or pore blocking effect. In ink-bottle pores, evaporation from the pore body is delayed because the connection to the bulk gas phase is obstructed by the condensed liquid in the necks. The wide body of the pore is unable to evaporate until the narrow neck empties during desorption and the pore size distribution cannot therefore be determined using the desorption branch of the isotherm which only gives information about the neck size (Figure 10B). Another possible evaporation regime from ink-bottle type pores is cavitation. ${ }^{71}$ Cavitation is expected to occur when the pore neck is lower than a critical size (estimated to be be ca. $5 \mathrm{~nm}$ for nitrogen at $77 \mathrm{~K}$ ), and usually corresponds to mesopores blocked by micropores. The pore body empties by diffusion while the pore neck remains filled. Therefore, in this case, the pressure at which desorption occurs has very little to do with the neck pore size. Although the shape of the isotherm and the large hysteresis suggest a cavitation-induced desorption, determining which mechanism (either pore blocking or cavitation), predominates is beyond the scope of this paper. Finally, the BET and t-plot analyses were used to determine the specific surface area and the micropore volume. As expected, the obtained values: $258 \mathrm{~m}^{2}$ $\mathrm{g}^{-1}$ and $0.1 \mathrm{~cm}^{3} \mathrm{~g}^{-1}$, respectively, were lower than for the organosilica particles of similar composition.

\subsection{Mechanism of particle formation}


From the experimental results presented above, the different steps involved in the formation of the core-shell organosilica particles can be summarized as follows. $\gamma$-MPS homogenization under vigorous stirring in the presence of tiny silica particles led to the formation of Pickering emulsion droplets around $50 \mathrm{~nm}$ in diameter with a narrow size distribution. According to the literature, ${ }^{48}$ the $\gamma$-MPS molecules hydrolyse and condense into basic solution to form negatively charged polymer chains with amphiphilic character. ${ }^{72}$ These silane oligomers being liquid and surface active, they form emulsion droplets in water through self-assembly. It was found that in the presence of inorganic particles, the size of the emulsion droplets can be significantly reduced due to preferential adsorption of the inorganic solid at the oil/water interface. ${ }^{67}$ Partial wetting of the silica particles by the oil phase (which is a prerequisite condition for the formation of a stable Pickering emulsion) is in turn promoted by in situ grafting of the organosilane molecules at their surface. Given the slow hydrolysis rate of organoalkoxysilanes in weakly basic solutions, only a fraction of the silane initially introduced contributed to the formation of the emulsion droplets at the beginning of the reaction. The droplets thus increased in size by consuming more $\gamma$-MPS precursor until the bulk monomer reservoir fully emptied, while concurrently new organosilica particles were generated through TEOS addition from the top organic layer. These tiny particles further adsorbed on the Pickering emulsion droplets leading to the formation of $\gamma$-MPS droplets coated by a monolayer of organosilica particles (Scheme 2). Further growth of the shell then took place through continuous deposition of silica and/or organosilica particles from solution leading to the formation of a dense and thick shell at the end of the reaction. Solid state ${ }^{29} \mathrm{Si}$ NMR revealed that the organosilane molecules were highly condensed at this stage with a majority of $\mathrm{T}^{2}$ and $\mathrm{T}^{3}$ species and no $\mathrm{T}^{1}$ or $\mathrm{T}^{0}$ units present. At last, pyrolysis of the templating organic ligand entrapped in the core and shell materials, created micropores in the shell and a inner hollow core connected to the exterior via the mesopore necks formed by 
the free space between the silica particles located at the interface and the micropores in the shell (Scheme 2, right hand side).

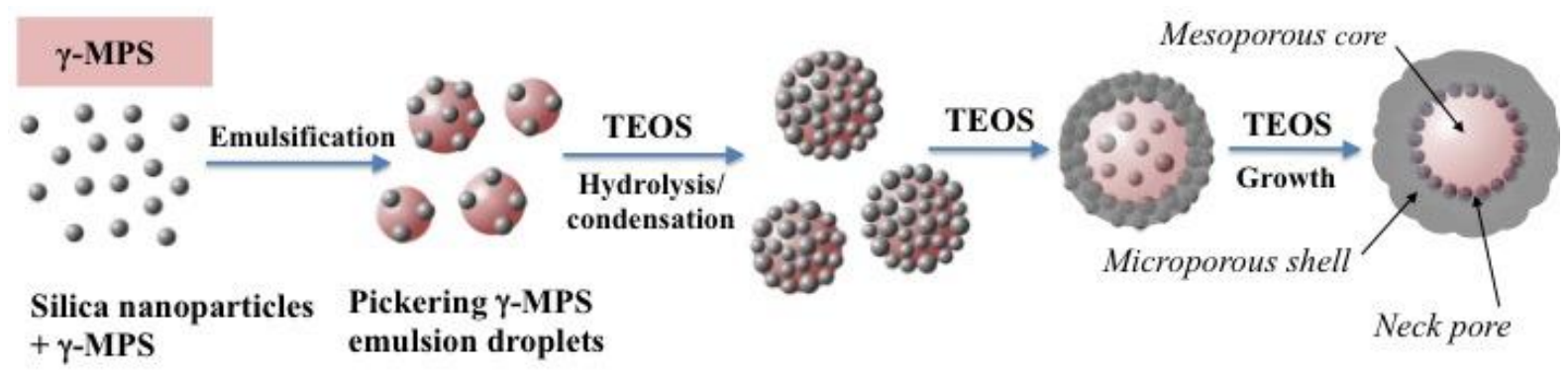

Scheme 2. Scheme illustrating the hypothetic mechanism of formation of core-shell organosilica nanoparticles by the L-arginine-catalyzed two-phase process using Pickering $\gamma$-MPS droplets as seeds.

\section{CONCLUSIONS AND OUTLOOKS}

In conclusion, we have presented here for the first time the surfactant-free synthesis of organosilica particles with nanometric dimensions directly in water, using the biphasic L-arginine process. In this process, L-arginine was used as catalyst in aqueous media, while a TEOS/ $\gamma$-MPS mixture was delivered heterogeneously from a top organic layer. Organosilica spheres with diameters comprised between 30 and $230 \mathrm{~nm}$ were successfully obtained by increasing the $\gamma$-MPS content in the silica source. The resulting hybrid particles had a rough surface and a high specific surface area, which increased by up to 25 times after calcination (e.g., from $27 \mathrm{~m}^{2}$ to $657 \mathrm{~m}^{2} \mathrm{~g}^{-1}$ for $10.1 \mathrm{~mol} \%$ of $\gamma$-MPS). The pore structure was characterized by $\mathrm{N}_{2}$ adsorption/desorption isotherms revealing the presence of micropores with pore volumes in the range $0.13-0.27 \mathrm{~cm}^{3} \mathrm{~g}^{-1}$. The process was next extended to the synthesis of core-shell organosilica particles in three steps. Tiny silica particles were first synthesized using a similar biphasic process where the mixture of sol-gel precursors was 
replaced by pure TEOS, and used to stabilize $\gamma$-MPS droplets, formed upon addition of the organosilane to the silica suspension. The Pickering emulsion droplets (around $50 \mathrm{~nm}$ in diameter) were finally used as seeds to grow a silica shell at their surface through TEOS hydrolysis/condensation, still in a biphasic process. $\mathrm{N}_{2}$ adsorption and TEM analyses of the core-shell particles after calcination, suggest a unique dual-porous structure composed of an inner mesoporous core and a micro/mesoporous silica shell with ink bottleneck pores. For both processes, controlling the $\gamma$-MPS concentration was key in order to form stable and monodisperse particles. Indeed, in the first route, a two high $\gamma$-MPS content adversely affected the colloidal stability of the organosilica spheres while in the second approach, a minimum amount of organosilane was required to adsorb all the silica particles at the surface of the Pickering emulsion droplets and form well-defined core-shell organosilica particles.

The presented method is easy to implement and highly versatile. The core diameter can be controlled by varying the oil volume fraction or the concentration of the silica nanoparticles. In addition, the method can be easily extended to other types of reactive oils (potentially combined with standard oils) and/or inorganic particles, and used to encapsulate drugs or organic compounds in pure aqueous media without any surfactant or co-solvent, which may open the door to a new class of inorganic capsules with potential applications in many areas of materials science.

\section{ACKNOWLEDGMENTS}

The financial support from the Chinese Scholarship Council is greatly acknowledged. X. G. Qiao thanks the Foundation of He'nan Educational Committee for partial financial support (17A150015). The authors warmly thank Antoine Thill for fruitful discussions. 


\section{REFERENCES}

1. A. Liberman, N. Mendez, W. C. Trogler, A. C. Kummel, Synthesis and surface functionalization of silica nanoparticles for nanomedicine. Surf. Sci. Rep. 2014, 69, 132-158.

2. V. R. K. Iler. The chemistry of silica. Solubility, polymerization, colloid and surface properties, and biochemistry, John Wiley and Sons Chichester, 1979.

3. T. Yanagisawa, T. Shimizu, K. Kuroda, C. Kato, The preparation of alkyltrimethylammonium-kanemite complexes and their conversion to microporous materials. Bull. Chem. Soc. Jpn. 1990, 63, 988-992.

4. C. T. Kresge, M. E. Leonowicz, W. J. Roth, J. C. Vartuli, J. S. Beck, Ordered mesoporous molecular sieves synthesized by a liquid-crystal template mechanism. Nature 1992, 359, 710-712.

5. Y. Wan, Zhao, On the Controllable Soft-Templating Approach to Mesoporous Silicates. Chem. Rev. 2007, 107, 2821-2860.

6. F. Hoffmann, M. Cornelius, J. Morell, M. Fröba, Silica-Based Mesoporous Organic-Inorganic Hybrid Materials. Angew. Chem. Int. Ed. 2006, 45, 3216-3251.

7. S. Shylesh, P. Samuel, S. Sisodiya, A. P. Singh, Periodic Mesoporous Silicas and Organosilicas: An Overview Towards Catalysis. Catal. Surv. Asia 2008, 12, 266-282.

8. R. Otero, D. Esquivel, M. Ulibarri, C. Jiménez-Sanchidrián, F. J. Romero-Salguero, J. M. Fernández, Adsorption of the herbicide S-Metolachlor on periodic mesoporous organosilicas. Chem. Eng. J. 2013, 228, 205-213.

9. I. Sierra, D. Perez-Quintanilla, Heavy metal complexation on hybrid mesoporous silicas: an approach to analytical applications. Chem. Soc. Rev. 2013, 42, 3792-3807. 
10. F. Tang, L. Li, D. Chen, Mesoporous Silica Nanoparticles: Synthesis, Biocompatibility and Drug Delivery. Adv. Mater. 2012, 24, 1504-1534.

11. M. Colilla, B. Gonzalez, M. Vallet-Regi, Mesoporous silica nanoparticles for the design of smart delivery nanodevices. Biomater. Sci. 2013, 1, 114-134.

12. S.-H. Wu, C.-Y. Mou, H.-P. Lin, Synthesis of mesoporous silica nanoparticles. Chem. Soc. Rev. 2013, 42, 3862-3875.

13. S. Gai, P. Yang, P. a. Ma, D. Wang, C. Li, X. Li, N. Niu, J. Lin, Fibrous-structured magnetic and mesoporous Fe3O4/silica microspheres: synthesis and intracellular doxorubicin delivery. J. Mater. Chem. 2011, 21, 16420-16426.

14. Z.-A. Qiao, L. Zhang, M. Guo, Y. Liu, Q. Huo, Synthesis of Mesoporous Silica Nanoparticles via Controlled Hydrolysis and Condensation of Silicon Alkoxide. Chem. Mater. 2009, 21, 3823-3829.

15. C. I. Zoldesi, A. Imhof, Synthesis of Monodisperse Colloidal Spheres, Capsules, and Microballoons by Emulsion Templating. Adv. Mater. 2005, 17, 924-928.

16. Q. Zhang, T. Zhang, J. Ge, Y. Yin, Permeable Silica Shell through Surface-Protected Etching. Nano Lett. 2008, 8, 2867-2871.

17. J. Zhang, M. Liu, A. Zhang, K. Lin, C. Song, X. Guo, Facile synthesis of mesoporous silica nanoparticles with controlled morphologies using water-acetone media. Solid State Sci. 2010, 12, 267-273.

18. J. E. Lee, N. Lee, H. Kim, J. Kim, S. H. Choi, J. H. Kim, T. Kim, I. C. Song, S. P. Park, W. K. Moon, T. Hyeon, Uniform Mesoporous Dye-Doped Silica Nanoparticles Decorated with Multiple Magnetite Nanocrystals for Simultaneous Enhanced Magnetic Resonance Imaging, Fluorescence Imaging, and Drug Delivery. J. Am. Chem. Soc. 2009, 132, 552-557. 19. L.-S. Wang, L.-C. Wu, S.-Y. Lu, L.-L. Chang, I. T. Teng, C.-M. Yang, J.-a. A. Ho, Biofunctionalized Phospholipid-Capped Mesoporous Silica Nanoshuttles for Targeted Drug 
Delivery: Improved Water Suspensibility and Decreased Nonspecific Protein Binding. ACS Nano 2010, 4, 4371-4379.

20. C.-H. Lee, S.-H. Cheng, I. P. Huang, J. S. Souris, C.-S. Yang, C.-Y. Mou, L.-W. Lo, Intracellular pH-Responsive Mesoporous Silica Nanoparticles for the Controlled Release of Anticancer Chemotherapeutics. Angew. Chem. Int. Ed. 2010, 49, 8214-8219.

21. F. Gai, T. Zhou, G. Chu, Y. Li, Y. Liu, Q. Huo, F. Akhtar, Mixed anionic surfactant-templated mesoporous silica nanoparticles for fluorescence detection of $\mathrm{Fe} 3+$. Dalton Trans. 2016, 45, 508-514.

22. K. Suzuki, K. Ikari, H. Imai, Synthesis of Silica Nanoparticles Having a Well-Ordered Mesostructure Using a Double Surfactant System. J. Am. Chem. Soc. 2003, 126, 462-463.

23. T. Yokoi, T. Karouji, S. Ohta, J. N. Kondo, T. Tatsumi, Synthesis of Mesoporous Silica Nanospheres Promoted by Basic Amino Acids and their Catalytic Application. Chem. Mater. 2010, 22, 3900-3908.

24. J. Wang, A. Sugawara-Narutaki, A. Shimojima, T. Okubo, Biphasic synthesis of colloidal mesoporous silica nanoparticles using primary amine catalysts. J. Colloid Interface Sci. 2012, 385, 41-47.

25. W. Stöber, A. Fink, E. Bohn, Controlled growth of monodisperse silica spheres in the micron size range. J. Colloid Interface Sci. 1968, 26, 62-69.

26. A. M. Jakob, T. A. Schmedake, A Novel Approach to Monodisperse, Luminescent Silica Spheres. Chem. Mater. 2006, 18, 3173-3175.

27. L. Wang, M. C. Estévez, M. O'Donoghu, W. Tan, Fluorophore-Free Luminescent Organosilica Nanoparticles. Langmuir 2008, 24, 1635-1639.

28. B. Fei, H. Lu, J. H. Xin, One-step preparation of organosilica@ chitosan crosslinked nanospheres. Polymer 2006, 47, 947-950. 
29. R. Vogel, P. P. T. Surawski, B. N. Littleton, C. R. Miller, G. A. Lawrie, B. J. Battersby, M. Trau, Fluorescent organosilica micro- and nanoparticles with controllable size. J. Colloid Interface Sci. 2007, 310, 144-150.

30. K. Y. T. Seet, R. Vogel, T. A. Nieminen, G. Knöner, H. Rubinsztein-Dunlop, M. Trau, A. V. Zvyagin, Refractometry of organosilica microspheres. Appl. Opt. 2007, 46, 1554-1561. 31. M. Nakamura, K. Ishimura, One-Pot Synthesis and Characterization of Three Kinds of Thiol-Organosilica Nanoparticles. Langmuir 2008, 24, 5099-5108.

32. E. Guihen, J. D. Glennon, Nanoparticles in Separation Science-Recent Developments. Anal. Lett. 2003, 36, 3309-3336.

33. M. Nakamura, M. Shono, K. Ishimura, Synthesis, Characterization, and Biological Applications of Multifluorescent Silica Nanoparticles. Anal. Chem. 2007, 79, 6507-6514. 34. C. R. Miller, R. Vogel, P. P. T. Surawski, S. R. Corrie, A. Ruhmann, M. Trau, Biomolecular screening with novel organosilica microspheres. Chem. Commun. 2005, 4783-4785.

35. C. R. Miller, R. Vogel, P. P. T. Surawski, K. S. Jack, S. R. Corrie, M. Trau, Functionalized Organosilica Microspheres via a Novel Emulsion-Based Route. Langmuir 2005, 21, 9733-9740.

36. M. Nakamura, K. Ishimura, Synthesis and Characterization of Organosilica Nanoparticles Prepared from 3-Mercaptopropyltrimethoxysilane as the Single Silica Source. J. Phys. Chem. C. 2007, 111, 18892-18898.

37. R. Rostamian, M. Najafi, A. A. Rafati, Synthesis and characterization of thiol-functionalized silica nano hollow sphere as a novel adsorbent for removal of poisonous heavy metal ions from water: Kinetics, isotherms and error analysis. Chem. Eng. J. 2011, $171,1004-1011$. 
38. Y. Liao, X. Wu, Z. Wang, R. Yue, G. Liu, Y. Chen, Composite thin film of silica hollow spheres and waterborne polyurethane: Excellent thermal insulation and light transmission performances. Mater. Chem. Phys. 2012, 133, 642-648.

39. S. Bai, J. Liu, J. Gao, Q. Yang, C. Li, Hydrolysis controlled synthesis of amine-functionalized hollow ethane-silica nanospheres as adsorbents for $\mathrm{CO} 2$ capture. Micropor. Mesopor. Mat. 2012, 151, 474-480.

40. Z. Deng, Z. Zhen, X. Hu, S. Wu, Z. Xu, P. K. Chu, Hollow chitosan-silica nanospheres as $\mathrm{pH}$-sensitive targeted delivery carriers in breast cancer therapy. Biomaterials 2011, 32, 4976-4986.

41. M. Okamoto, H. Huang, Formation of hollow silica spheres with ordered mesoporous structure by treatment with dimethyl carbonate for selective decomposition of mesoporous silica core. Micropor. Mesopor. Mat. 2012, 163, 102-109.

42. A. Arkhireeva, J. N. Hay, Synthesis of sub-200 nm silsesquioxane particles using a modified Stober sol-gel route. J. Mater. Chem. 2003, 13, 3122-3127.

43. Y. Takeda, Y. Komori, H. Yoshitake, Direct stöber synthesis of monodisperse silica particles functionalized with mercapto-, vinyl- and aminopropylsilanes in alcohol-water mixed solvents. Colloids Surf. A Physicochem. Eng. Asp. 2013, 422, 68-74.

44. J. G. Croissant, X. Cattoen, J.-O. Durand, M. Wong Chi Man, N. M. Khashab, Organosilica hybrid nanomaterials with a high organic content: syntheses and applications of silsesquioxanes. Nanoscale 2016, 8, 19945-19972.

45. A. P. R. Johnston, B. J. Battersby, G. A. Lawrie, M. Trau, Porous functionalised silica particles: a potential platform for biomolecular screening. Chem. Commun. 2005, 848-850. 46. Y.-G. Lee, J.-H. Park, C. Oh, S.-G. Oh, Y. C. Kim, Preparation of Highly Monodispersed Hybrid Silica Spheres Using a One-Step Sol-Gel Reaction in Aqueous Solution. Langmuir 2007, 23, 10875-10878. 
47. T.-S. Deng, Q.-F. Zhang, J.-Y. Zhang, X. Shen, K.-T. Zhu, J.-L. Wu, One-step synthesis of highly monodisperse hybrid silica spheres in aqueous solution. J. Colloid Interface Sci. 2009, 329, 292-299.

48. C. van der Wel, R. K. Bhan, R. W. Verweij, H. C. Frijters, Z. Gong, A. D. Hollingsworth, S. Sacanna, D. J. Kraft, Preparation of Colloidal Organosilica Spheres through Spontaneous Emulsification. Langmuir 2017, 33, 8174-8180.

49. M. Segers, N. Arfsten, P. Buskens, M. Moller, A facile route for the synthesis of sub-micron sized hollow and multiporous organosilica spheres. RSC Adv. 2014, 4, 20673-20676.

50. R. M. Ottenbrite, J. S. Wall, J. A. Siddiqui, Self-Catalyzed Synthesis of Organo-Silica Nanoparticles. J. Am. Ceram. Soc. 2000, 83, 3214-3215.

51. Z. Meng, C. Xue, Q. Zhang, X. Yu, K. Xi, X. Jia, Preparation of Highly Monodisperse Hybrid Silica Nanospheres Using a One-Step Emulsion Reaction in Aqueous Solution. Langmuir 2009, 25, 7879-7883.

52. K. D. Hartlen, A. P. T. Athanasopoulos, V. Kitaev, Facile Preparation of Highly Monodisperse Small Silica Spheres (15 to >200 nm) Suitable for Colloidal Templating and Formation of Ordered Arrays. Langmuir 2008, 24, 1714-1720.

53. T. Yokoi, J. Wakabayashi, Y. Otsuka, W. Fan, M. Iwama, R. Watanabe, K. Aramaki, A. Shimojima, T. Tatsumi, T. Okubo, Mechanism of Formation of Uniform-Sized Silica Nanospheres Catalyzed by Basic Amino Acids. Chem. Mater. 2009, 21, 3719-3729.

54. X. G. Qiao, P. Y. Dugas, B. Charleux, M. Lansalot, E. Bourgeat-Lami, Synthesis of Multipod-like Silica/Polymer Latex Particles via Nitroxide-Mediated Polymerization-Induced Self-Assembly of Amphiphilic Block Copolymers. Macromolecules 2015, 48, 545-556.

55. J. H. de Boer, B. G. Linsen, T. J. Osinga, Studies on pore systems in catalysts: VI. The universal t curve. J. Catal. 1965, 4, 643-648. 
56. T. Yokoi, Y. Sakamoto, O. Terasaki, Y. Kubota, T. Okubo, T. Tatsumi, Periodic Arrangement of Silica Nanospheres Assisted by Amino Acids. J. Am. Chem. Soc. 2006, 128, 13664-13665.

57. S. Fouilloux, J. Daillant, A. Thill, Single step synthesis of 5-30nm monodisperse silica nanoparticles: Important experimental parameters and modeling. Colloids Surf. A Physicochem. Eng. Asp. 2012, 393, 122-127.

58. T. P. Beebe, P. Gelin, J. T. Yates Jr, Infrared spectroscopic observations of surface bonding in physical adsorption: The physical adsorption of $\mathrm{CO}$ on $\mathrm{SiO} 2$ surfaces. Surf. Sci. 1984, $148,526-550$.

59. N. Negrete Herrera, J.-M. Letoffe, J.-P. Reymond, E. Bourgeat-Lami, Silylation of Laponite clay particles with monofunctional and trifunctional vinyl alkoxysilanes. J. Mater. Chem. 2005, 15, 863-871.

60. C. C. M. C. Carcouët, M. W. P. van de Put, B. Mezari, P. C. M. M. Magusin, J. Laven, P. H. H. Bomans, H. Friedrich, A. C. C. Esteves, N. A. J. M. Sommerdijk, R. A. T. M. van Benthem, G. de With, Nucleation and Growth of Monodisperse Silica Nanoparticles. Nano Lett. 2014, 14, 1433-1438.

61. N. Nishiyama, R. Shick, H. Ishida, Adsorption behavior of a silane coupling agent on colloidal silica studied by gel permeation chromatography. J. Colloid Interface Sci. 1991, $143,146-156$.

62. K. Ni, G. Shan, Z. Weng, N. Sheibat-Othman, G. Fevotte, F. Lefebvre, E. Bourgeat-Lami, Synthesis of hybrid core-shell nanoparticles by emulsion (co)polymerization of styrene and gamma-methacryloxypropyltrimethoxysilane. Macromolecules $\mathbf{2 0 0 5}, 38$, 7321-7329.

63. E. J. Kappert, H. J. M. Bouwmeester, N. E. Benes, A. Nijmeijer, Kinetic Analysis of the Thermal Processing of Silica and Organosilica. J. Phys. Chem. B 2014, 118, 5270-5277. 
64. H. Zhang, H. Xu, M. Wu, Y. Zhong, D. Wang, Z. Jiao, A soft-hard template approach towards hollow mesoporous silica nanoparticles with rough surfaces for controlled drug delivery and protein adsorption. J. Mater. Chem. B 2015, 3, 6480-6489.

65. A. van Blaaderen, A. Vrij, Synthesis and Characterization of Monodisperse Colloidal Organo-silica Spheres. J. Colloid Interface Sci. 1993, 156, 1-18.

66. J. Wang, A. Sugawara-Narutaki, M. Fukao, T. Yokoi, A. Shimojima, T. Okubo, Two-Phase Synthesis of Monodisperse Silica Nanospheres with Amines or Ammonia Catalyst and Their Controlled Self-Assembly. ACS Appl. Mater. Interfaces 2011, 3, $1538-1544$.

67. S. Sacanna, W. K. Kegel, A. P. Philipse, Thermodynamically Stable Pickering Emulsions. Phys. Rev. Lett. 2007, 98, 158301.

68. S. Sacanna, W. K. Kegel, A. P. Philipse, Spontaneous Oil-in-Water Emulsification Induced by Charge-Stabilized Dispersions of Various Inorganic Colloids. Langmuir 2007, 23, 10486-10492.

69. S. J. Gregg, K. S. W. Sing. Adsorption, Surface Area and Porosity. 2nd ed., Academic: New York, 1982, 287.

70. J. C. Groen, L. A. A. Peffer, J. Pérez-Ramírez, Pore size determination in modified micro- and mesoporous materials. Pitfalls and limitations in gas adsorption data analysis. Micropor. Mesopor. Mat. 2003, 60, 1-17.

71. P. I. Ravikovitch, A. V. Neimark, Experimental Confirmation of Different Mechanisms of Evaporation from Ink-Bottle Type Pores: Equilibrium, Pore Blocking, and Cavitation. Langmuir 2002, 18, 9830-9837.

72. D. J. Kraft, J. W. J. de Folter, B. Luigjes, S. I. R. Castillo, S. Sacanna, A. P. Philipse, W. K. Kegel, Conditions for Equilibrium Solid-Stabilized Emulsions. J. Phys. Chem. B 2010, $114,10347-10356$. 
